\title{
Correlating the trends of COVID-19 spread and air quality during lockdowns in Tier-I and Tier-II cities of India-lessons learnt and futuristic strategies
}

\author{
Mangottiri Vasudevan ${ }^{1} \cdot$ Narayanan Natarajan $^{2}$ (D) Sugashini Masillamani Selvi ${ }^{2} \cdot$ Kesavan Ravikumar $^{2} \cdot$ \\ Arun Dharshini Rajendran ${ }^{2} \cdot$ Anushya Banu Bagavathi $^{2}$
}

Received: 26 May 2021 / Accepted: 14 August 2021 / Published online: 21 September 2021

(C) The Author(s), under exclusive licence to Springer-Verlag GmbH Germany, part of Springer Nature 2021

\begin{abstract}
The present study focuses on the impact of early imposed lockdowns and following unlocking phases on the status of air quality in six Tier-I and nine Tier-II cities of India as compared to the pre-lockdown measures. Furthermore, the study highlights the possible correlation of air quality index (AQI) with the initial trend of COVID-19 issues including the vaccination cases. Based on the statistical data analysis, we observed that the long-term averages for representing the short-term pre-lockdown conditions can impose a healing effect to the observed anomalies in air pollution data. However, the reduction in air pollution during the imposed lockdown series was only a phenomenal consequence, and the trends started reversing during the later phases of partial unlocking, where the correlation showed reversing trends. Being a yearly averaged parameter, the marginal reductions in the exceedance factor (EF) alone could not dictate air quality compared to the AQI. As there is incoherent variability in the pollutant distributions among the cities during various phases of the study, the trend analysis served as a preferable criterion to choose the preferred sources of variations. Based on the results, the correlation analysis revealed that air quality expressed in terms of AQI can act as an important precursor to estimate the critical phase of COVID-19 spread and the effectiveness of various control measures taken during each phase. Based on our proposed ranking, Kolkata and Patna are ranked first in the Tier-I and Tier-II cities respectively according to their responsiveness to the various institutionalized restrictions in terms of air quality parameters.
\end{abstract}

Keywords Air quality $\cdot$ AQI $\cdot$ COVID-19 pandemic $\cdot$ Exceedance factor $\cdot$ Lockdown

\section{Introduction}

The COVID-19 pandemic situation due to the uncontrolled spread and attack of novel coronavirus (SARS-CoV-2) during 2020-2021 has created a totally unprecedented global crisis especially in the people's lives, interactions, businesses and economics (Dutheil et al. 2020; Gautam 2020). The deadly impact of this virus on human health has been reported as an acute respiratory disease affecting the lungs causing

Responsible Editor: Lotfi Aleya

Narayanan Natarajan

itsrajan2002@yahoo.co.in

1 Department of Civil Engineering, Bannari Amman Institute of Technology, Sathyamangalam, Erode, Tamil Nadu 638401, India

2 Department of Civil Engineering, Dr. Mahalingam College of Engineering and Technology, Pollachi, Tamil Nadu 642003, India pneumonia and also triggering further damages to the kidney and heart. The high mortality rate of this infection has been associated with cardiac diseases, cancers and immunodeficiency (Chen et al. 2020;v Wang et al. 2020). As on July 25, 2021, the coronavirus has attacked more than 194.5 million people with more than 13.78 million active cases and snatched the lives of 4.17 million people worldwide. The rapid spreading rate and its associated fatal mortality rate make it challenging to restrain the deadly impacts even after introducing specific vaccines at a later stage (Link 1 (2021)). As a precautionary and temporary arrangement, many countries have imposed nationwide lockdowns in order to restrict people's movement and thereby reduce the chances of possible infections through interactions. Though impacting the state economics adversely, such restrictions without interrupting services such as food, medical and other emergency systems are often interpreted to be the best possible interventions to regularize the necessary follow-up actions (Bao and Zhang 2020; Sharma et al. 2021). 
However, some of the early-affected countries have implemented lockdown only after realising the extent of disaster with increasing death tolls, owing to peer financial pressure, over-dependency on economic strategies and lack of preparedness with sufficient infrastructure to enforce mass restrictions. Inevitably, by virtue of restricted human interventions, such institutional restrictions have long-term impacts not only on the socio-economic scenario but also on the total environmental quality and performance of natural recovery and remediation systems.

Air pollution has been an acute problem that is inflicting the lives of people every year, especially in all the metropolitan cities (Louati et al. 2018). It is particularly important for India as $35 \%$ of the deaths in 2015 reported were due to air pollution (Sharma et al. 2019) and 9 out of the 10 most polluted cities listed released by the World Health Organization (WHO) are from the Indian sub-continent (Yuda 2019). Being a country that imposed national lockdowns much before the major hit, India has faced many challenges and advantages in the fight against COVID-19 during the year 2020. The major boon, however, was the remarkable improvements in air and water quality of major cities during and after the periods of lockdowns. Hypothetically, any significant improvement in the major air quality parameters of the atmosphere can possibly contribute towards better environment and public health. Therefore, it is important to observe the spatiotemporal trends of various air quality parameters under the prevailing situations in order to derive any plausible correlations that can significantly mark conclusive remarks and futuristic predictions.

Most of the literature dealing with air quality assessment would typically include trend analysis based on long-term monitoring data in order to check the consistency of the results. Sharma et al. (2020) demonstrated the changing trends in air pollution over varying geographical locations in India by analysing the annual growth rate of sulphur dioxide $\left(\mathrm{SO}_{2}\right)$, $\mathrm{NO}_{2}$ and $\mathrm{PM}_{2.5}$ from 2015 to 2018. Markandeya et al. (2021) investigated the seasonal variations in the air pollution levels in Lucknow and also assessed the ambient air quality of the city with emphasis on the impacts of $\mathrm{PM}_{10}, \mathrm{PM}_{2.5}, \mathrm{SO}_{2}$, $\mathrm{NO}_{2}, \mathrm{~Pb}, \mathrm{Ni}$ and aerosols on the health of the people from 2010 to 2019.

However, in the case of the COVID-19 pandemic, the response time has been quite short to realize the apparent changes in air quality (in terms of concentration of air pollutants) during the imposed lockdown due to drastic change in social activities. This necessitates evolution of short-term trend analysis to capture the nature and trend of changing atmospheric behaviour during different periods of locking and unlocking events. The waning in the air pollution was reported in various parts of the globe as caused by the constrained social and economic activities during the periods of lockdown (Saadat et al. 2020; Zambrano-Monserrate et al. 2020). In India, the prominent features of the lockdowns during March-May 2020 were observed like almost complete ban on all modes of transport, closure of public places of crowding (tourism spots, shopping malls, restaurants, theatres, marriage halls and religious centres) and restricted operation of factories. However, the essential commodities were supplied in a conservative manner with various initiatives from local vendors. During this period, several studies have been conducted focusing on the air pollution status in different cities across the Indian sub-continent under various lockdown phases (Table 1). Being the national capital territory (NCT) and illfamed city for air pollution, Delhi has been a point of attraction for almost all early lockdown studies. Mahato et al. (2020) was one of the early studies highlighting on the impact of short-period lockdown on the air quality in Delhi. Sharma et al. (2020) reported significant improvement in air quality based on the short periods of analysis, before lockdown (10 days, March 11-20, 2020) and during lockdown period (54 days, March 25 to May 17, 2020) in seven selected cities of Rajasthan, India.

There is an increasing pile of research articles reporting the immediate responses of lockdown events on the local environmental quality, especially on the air quality (Agarwal et al. 2020; Menut et al. 2020; Ropkins and Tate 2021; Vali et al. 2021). Gautam (2020) has reported the significant reduction in the levels of nitrogen dioxide $\left(\mathrm{NO}_{2}\right)$ in the Asian and European countries during the pandemic lockdowns. Ambade et al. (2021) compared the levels of black carbon, polycyclic aromatic hydrocarbons and particulate matter $\left(\mathrm{PM}_{2.5}\right)$ concentrations and the associated health risk assessment during the normal days, lockdown period and unlock 1.0 at Sakchi, Jamshedpur city. Gautam et al. (2021) have reported that there is a positive correlation between the level of air pollution of a region and the lethality of COVID19 that may aggravate the death rate in the future. They also reported that high level of $\mathrm{PM}_{2.5}$ has a significant correlation with COVID-19 mortality compared with $\mathrm{PM}_{10}$. Apart from this, there are many studies focused on individual states and cities of India such as Bangalore (Ramasamy and Jayakumar 2020), West Bengal (Roy and Singha 2020) and Bhubaneswar (Panda et al. 2021).

In addition to the individual trend analysis studies, investigations on the comparative status of multiple cities are also being studied widely. Agarwal et al. (2020) conducted a comparative study on the air quality status in six Indian and six Chinese cities before and during the COVID-19 lockdown period based on real-time monitoring data in terms of the concentration of particulate matter $\left(\mathrm{PM}_{2.5}\right)$ and nitrogen dioxide $\left(\mathrm{NO}_{2}\right)$. Ravindra et al. (2021) studied the impact of restrictions during various phases of COVID-19 lockdown and unlocking phases on daily mean $\mathrm{PM}_{2.5}$ concentrations in five Indian megacities (New Delhi, Chennai, Kolkata, Mumbai and Hyderabad). They observed maximum reduction in 


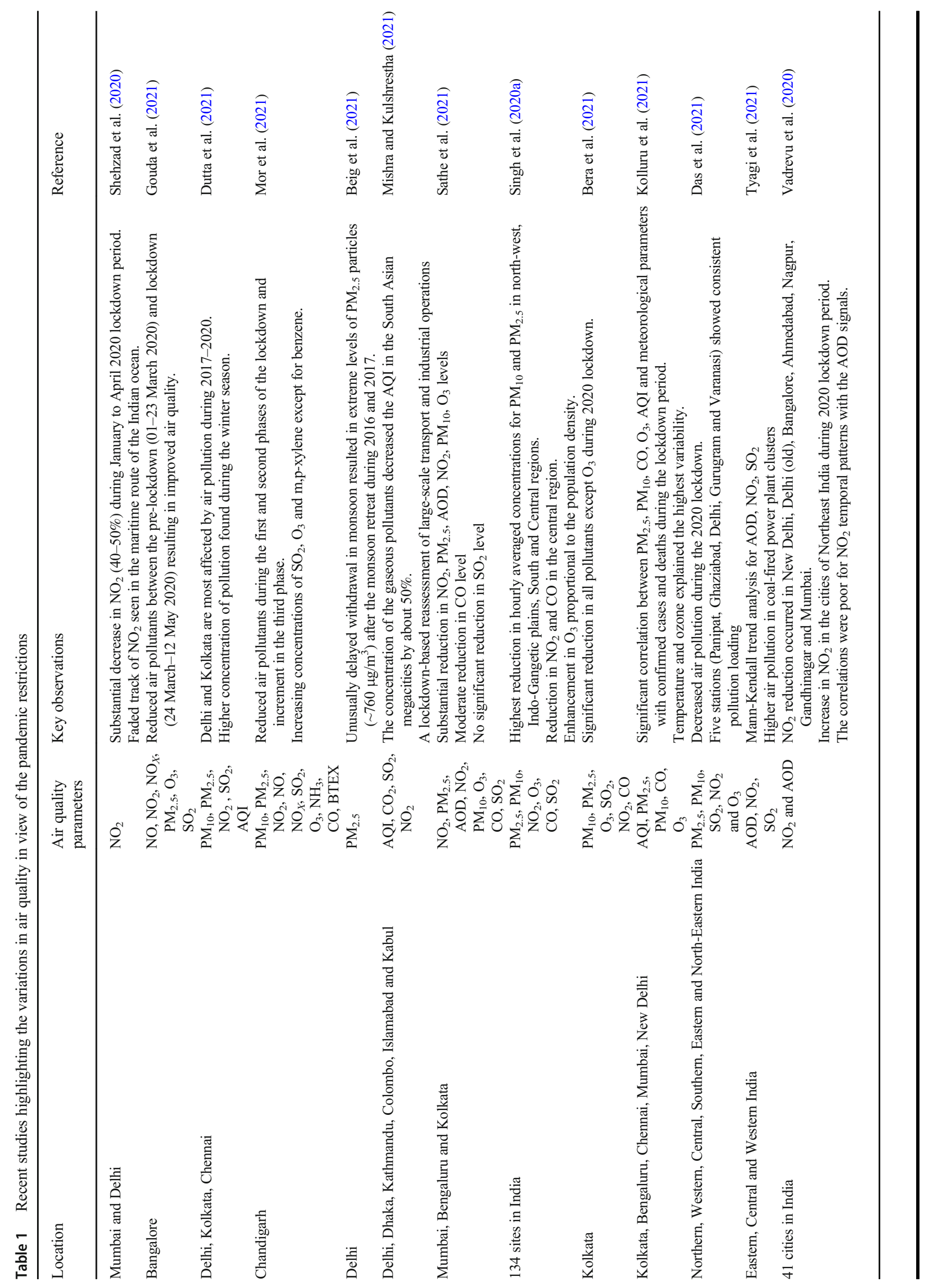


$\mathrm{PM}_{2.5}$ concentrations in Kolkata, followed by Mumbai, Chennai and New Delhi during the lockdown period. A more detailed study was reported by Pant et al. (2020) on air quality in four major metropolitan cities in India (Delhi, Mumbai, Kolkata and Chennai) from January 1, 2020, to May 31, 2020, by analysing the particulate matter $\mathrm{PM}_{2.5}$ and $\mathrm{PM}_{10}, \mathrm{NO}_{2}, \mathrm{NH}_{3}, \mathrm{SO}_{2}, \mathrm{CO}$ and ozone levels. Gautam et al. (2021) also studied the variations in five air pollutants, $\left(\mathrm{PM}_{10}\right.$, $\mathrm{PM}_{2.5}, \mathrm{SO}_{2}, \mathrm{NO}_{2}$ and $\mathrm{CO}$ ) during the pandemic over eight most polluted cities across India. In another study, the diurnal variations in six major air pollutants across the six geographical regions of India during March-May 2020 were reported by Singh et al. (2020a). However, their study was focused only on the margin of reduction with limited discussion on the scope of correlation analysis.

Apart from the direct measurements of the pollutant concentrations, there were also reports on variation in air quality in terms air quality index (AQI), a non-dimensional parameter. Mahato et al. (2020) highlighted the drastic reduction in national air quality index (NAQI) in various parts of Delhi in response to the early lockdowns. Selvi et al. (2020) analysed the daily and monthly variations of AQI of sixteen cities located in India. They reported that the improvement in the overall air quality after 21 days of lockdown in all the selected cities necessitates the study of variations in specific to sociocultural backgrounds. Gautam et al. (2020) reported notable differences in the AQI of Delhi, Haryana and Uttar Pradesh from 17th February 2020 to 4th May 2020. Similarly, Ramasamy and Jayakumar (2020) have reported sharp declining trends in AQI values during the initial phase of lockdown in the city of Bangalore. Roy and Singha (2020) addressed the impact of common air pollutants in the city of Siliguri in West Bengal, India, and reported the criticality of dust particles in the atmosphere $\left(\mathrm{PM}_{10}\right.$ and $\left.\mathrm{PM}_{2.5}\right)$ using exceedance factor (EF) and AQI based on the trend in the average annual concentrations. Singh et al. (2020b) used kernel density estimation (KDE) and spatial inter-correlation between the diurnal variations of pollutants across the six geographical regions of India during March-May 2020. Results from the satellitebased studies about 41 cities of India by Vadrevu et al. (2020) reported that the variations in $\mathrm{NO}_{2}$ can better provide the characteristic trend of air pollution in major Indian cities in comparison with the aerosol optical depth (AOD). This is based on an extensive data analysis such as paired $t$-test and autoregressive moving average (ARMA) analysis of the QGIS-based data for a period of 3 months (MarchMay 2020) where reductions up to $13 \%$ were caused by the short-term imposed lockdown. In a similar study, the responses of climate on the COVID-19 restrictions were studied by Ranjan et al. (2020) in terms of reduction in AOD indicating reduced human activities in the Indian metropolitan cities. They also reported that continued industrial operations may cause positive anomalies in AOD even during the imposed lockdown periods. As evident from these studies, one can certainly infer that the lockdown was a blessing in disguise at least to the air and water environments (Kumari and Toshniwal 2020; Mandal and Pal 2020; Bherwani et al. 2020; Girdhar et al. 2021).

As the second wave of COVID-19 has been continuing the destruction in a massive way, there are many upcoming studies showcasing the enhanced dimensions of COVID-19 impacts on a global scale. As evident from numerous medical and economic reports, the impact of air pollution incidents on public health has been a critical topic of concern for many populated cities of India. However, deriving a generic relationship between air pollution and COVID-19 cases has been an emerging scope of study to arrive at strategic conclusions pertaining to the dynamic colloidal (or aerosol) characteristics of the coronavirus and to check the effectiveness of the standard operating protocols (SOP) set forth during various phases of the pandemic. Only a few studies have attempted so far to relate COVID-19 spread to the atmospheric quality and meteorological conditions. Sharma et al. (2021) examined the relationship between the COVID-19 confirmed cases, deaths and meteorological factors including air pollution for the top 10 infected countries using advanced econometric methods. Wiśniewski et al. (2021) analysed the impact of weather factors such as temperature, relative humidity, wind speed and ground-level ozone concentration on the number of COVID-19 cases in Warsaw, Poland, using the Spearman rank correlation test. Interestingly, they observed an inverse correlation between ground-level ozone concentration and the daily number of COVID-19 cases. In a similar study, Bilal et al. (2020) have analysed the relationship between climate, pollution and COVID-19 cases in Germany using wavelet transform coherence (WTC). They suggested that $\mathrm{PM}_{10}$ and $\mathrm{O}_{3}$ are the main determinants associated with the outbreak of COVID-19. Kutralam-Muniasamy et al. (2021) performed statistical correlation tests to investigate the impacts of two short-term lockdown events on air pollution and mortality trends in Mexico City. They recommended enforcing new air pollution regulations based on the rise in concentration of some pollutants with increase in mortality rate. However, generalization of such statistical interpretations is likely limited as these studies are spatiotemporally constrained and therefore advocates unique economic and medical policy strategies.

The air pollution in growing cities is likely to be increasing due to the increase in human activities resulting in higher emissions from vehicles, industries, power plants, etc. To worsen the scenario, statistics says that the largest number of COVID-19 cases is reported from the cities having more population, thus pointing towards the higher risk of community spread. However, a mere comparison of major cities of India based on population into Tier-I and Tier-II categories may not illustrate the real scenario because the nature of pandemic spread and the extent of preventive and supportive 
mechanisms may not be similar in many cities. Most of the early reports about air quality variations during the lockdown phases were highly abstract and limited in scope with only focus on representing the notable variations in trends, rather than investigating on the possible correlations, consequences and combating measures.

While the lockdown phases in 2020 are featured with restrictions on social activities and public transport by anticipating some deadly impacts, the unlock phases in late 2020 are implemented with gradual release of restrictions for public gathering and commercial/industrial activities based on projected declining spread of COVID-19. In addition, the unlock phases in early 2021 are associated with the introduction of precautionary vaccines throughout the country as a massive drive. However, there are still ambiguities in accounting for the impacts of imposed lockdowns as well as vaccinations towards mitigating the COVID-19 spread as witnessed by the unexpected rise of positive confirmed cases while vaccination drive was expanding in India. Since the cities are considered air pollution hotspots, the present study focuses on analysing the trend and correlation of air quality and COVID-19 spread in all major Indian cities (six cities under Tier-I and nine cities under Tier-II categories) over the various phases of pre-locking, locking and unlocking events in 2020. In this study, we also aim to investigate on the correlation between the COVID-19 risk parameters and air quality indices using various statistical measures such as the exceedance factor, the $t$-test, the ANOVA test and the Pearson product moment correlation analysis for the available dataset.

\section{Materials and methods}

\section{Study area}

The geographical details of the 15 selected Indian cities are provided in Table 2 and the geographical location of the same is provided in Fig. 1. We follow the generic classification of Indian cities as Tier-I and Tier-II which is based on population and infrastructural development. The six Tier-I cities are Chennai, Mumbai, Delhi, Kolkata, Bengaluru and Hyderabad, while the nine Tier-II cities are Ahmedabad, Bhopal, Chandigarh, Guwahati, Jaipur, Lucknow, Patna, Thiruvananthapuram and Visakhapatnam. As observed from Fig. 1, by virtue of the strategic location, analysis of these cities can substantially provide an overview of the national status of air pollution in the midst of COVID-19 (Link 2 (n.d.)). It is to be noted that during the early hit of COVID19 , most of these cities were involved in identifying the local epicentres of the spread by identifying most infected locations under the red zone category, even before the lockdowns were officially announced (Link 3 (n.d.)). In addition, numerous containment zones were declared to minimize the social interaction with strict police patrolling and taxing fine for the offenders (Link 4 (n.d.); Link 5 (n.d.)). Details of the containment zone status during the peak of the first COVID19 wave are mentioned in Table 2.

\section{Various lockdown and unlocking phases in India}

As an unconventional strategy by the central government of India to combat against the virus spread, there were four national-level imposed lockdown events (LD1-LD4) between March and May 2020 (Table 3). To make the statistical analysis more coherent and unbiased, we have defined the pre-lockdown period in three terms (BLD1, BLD2 and BLD3) based on the extent of time period considered for calculating the average values of concentration and other indices. The prominent socio-economic features of the lockdowns during this period were observed as complete ban on all modes of transport, closure of public places of crowding (tourism spots, shopping malls, restaurants, theatres, marriage halls and religious centres) and restricted operation of factories. However, a conservative supply of the essential commodities to the people was ensured with the help of various non-government organizations and self-help groups. Following the lockdown, about ten progressive unlocking periods (UL1-UL10) were identified for the period from June 2020 to April 2021 in order to capture the recent trends in air quality as well as COVID-19 spread, especially during the vaccination drive.

\section{Data collection}

The present study utilized an extensive database of 12 major air pollutants $\left(\mathrm{PM}_{2.5}, \mathrm{PM}_{10}, \mathrm{NO}, \mathrm{NO}_{2}, \mathrm{NO}_{x}, \mathrm{NH}_{3}\right.$, $\mathrm{CO}, \mathrm{SO}_{2}, \mathrm{O}_{3}$, benzene, toluene and xylene) which are regularly included in the air quality monitoring networks established by the Central Pollution Control Board (CPCB) covering 703 air quality stations across 307 cities of India (Sharma et al. 2020). The required database of daily averaged $(24 \mathrm{~h})$ concentrations is availed from their online portal (Link 6 (2021)) for the entire study duration. After downloading the spread sheets, the dataset is primarily filtered for eliminating rows with missing data and rearranged as per the priority considerations. Similarly, the daily databases of air quality index (AQI) for the selected cities were also collected from the online portal (Link 7 (2021)) as separate customized spread sheets. The daily reported counts of COVID-19 positive cases, recovery cases, mortality cases and vaccination details were accessed from the website (Link 8 (2021)) which is regularly updating based state bulletins and official handles. 


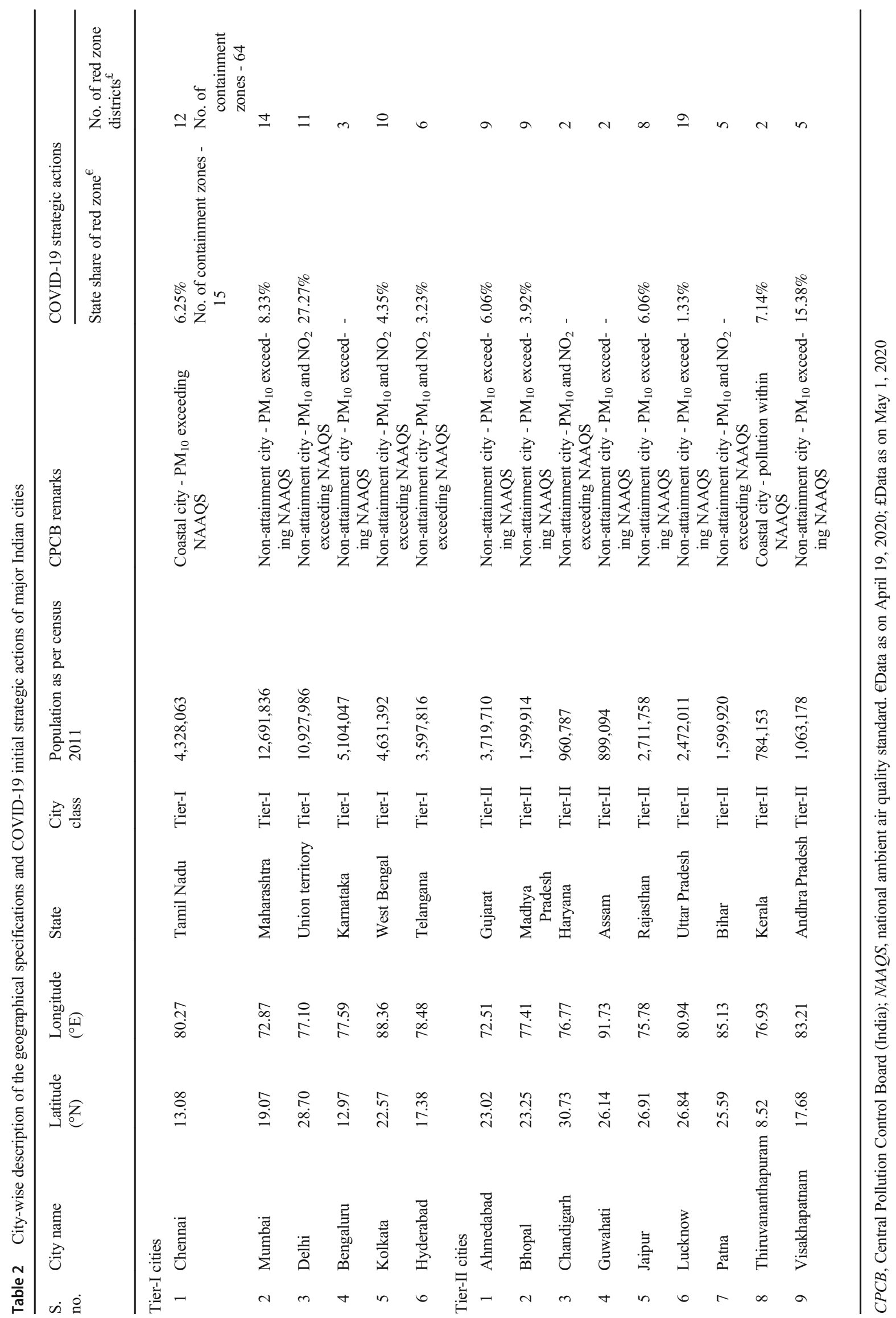




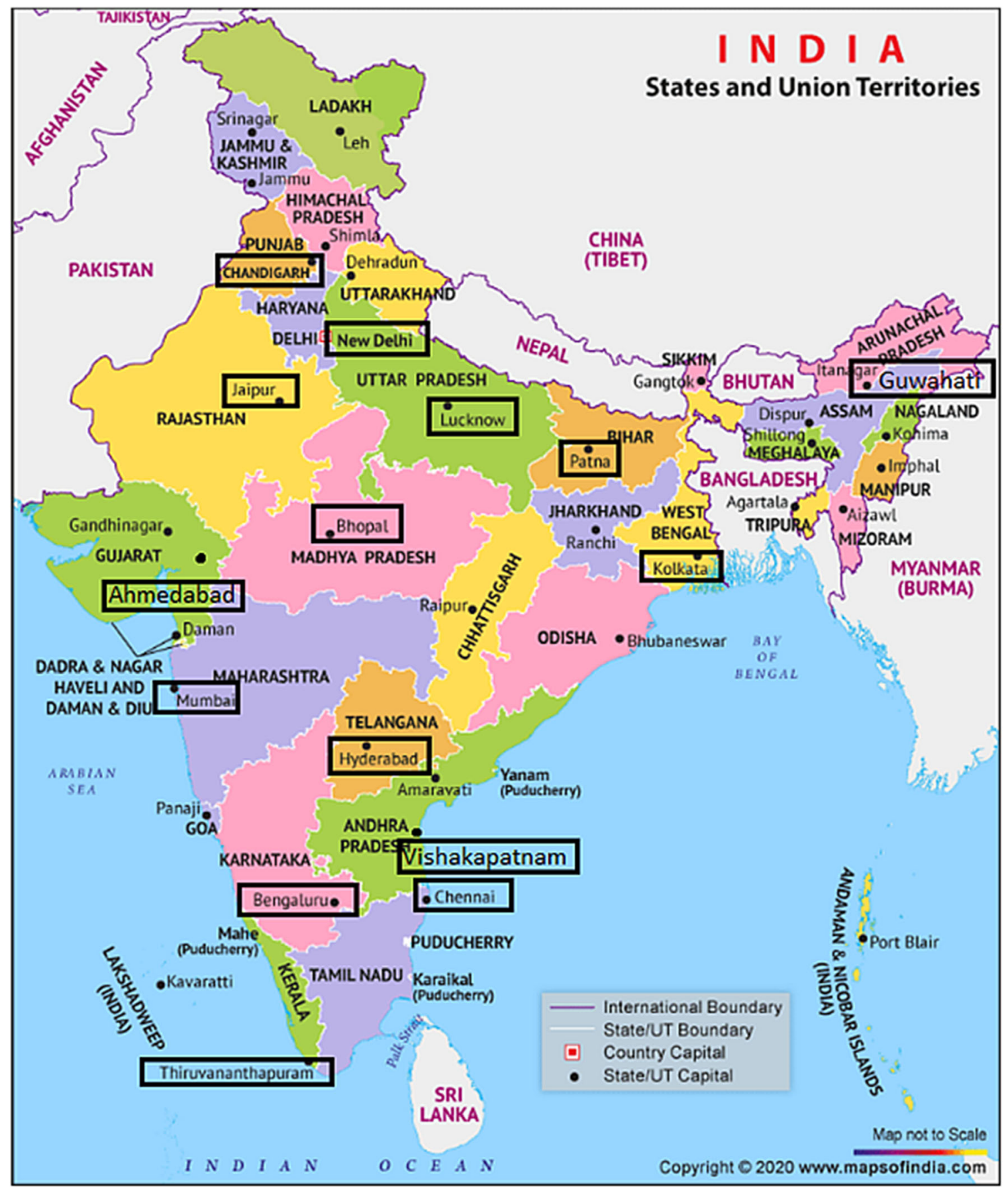

Fig. 1 Geographical location of the chosen cities (marked in black box)

\section{Data analysis}

\section{Air quality index}

The national ambient air quality index (AQI) has been conceived as an effective tool for depicting the real-time generic nature of air quality in terms of the corresponding ambient concentrations of the identified pollutants (CPCB 2016). The daily reported AQI values for all the 15 cities were initially analysed for spatiotemporal variations in terms of standard deviations from their arithmetic average values. This is particularly emphasized to capture the reliability of long-term monitored data during the pre-lockdown phase in terms of three timelines (BLD1, BLD2 and BLD3). Furthermore, the AQI values were averaged to the corresponding periods of lockdowns and unlocking phases to elucidate their dependencies on specific pollutants. The recommended AQI categories were accepted as the direct indicators of the severity of various air pollutants with their associated likely health impacts such as AQI: 0-50 (good), 51-100 (satisfactory), 101-200 
Table 3 Details of the various lockdown and unlock phases in India

\begin{tabular}{|c|c|c|c|c|c|}
\hline Phase & Start date & End date & No. of days & Notation & Major remarks \\
\hline 1 & 01 January 2019 & 24 March 2020 & 449 & BLD1 & Period considered for long-term average \\
\hline 2 & 01 January 2020 & 24 March 2020 & 84 & BLD2 & Period considered for short-term average \\
\hline 3 & 01 March 2020 & 24 March 2020 & 24 & BLD3 & Period considered for very short-term average \\
\hline 4 & 25 March 2020 & 14 April 2020 & 21 & LD1 & $\begin{array}{l}\text { Complete curfew-COVID-positive cases increased } \\
\text { from } 600 \text { to } 10,000 \text {; a few hotspots located with a } \\
\text { test positivity ratio of } 4.7 \%\end{array}$ \\
\hline 5 & 15 April 2020 & 3 May 2020 & 19 & LD2 & $\begin{array}{l}\text { More hotspots in Maharashtra, Gujarat, Delhi, } \\
\text { Rajasthan, Madhya Pradesh, Tamil Nadu and } \\
\text { Uttar Pradesh; partial relaxation to selected shops }\end{array}$ \\
\hline 6 & 4 May 2020 & 17 May 2020 & 14 & LD3 & $\begin{array}{l}\text { More red zones in Delhi, Mumbai, Bengaluru, } \\
\text { Chennai and Ahmedabad; cases increased from } \\
42,533 \text { to } 85,940\end{array}$ \\
\hline 7 & 18 May 2020 & 31 May 2020 & 14 & LD4 & $\begin{array}{l}\text { Reported } 5,000 \text { fatalities; administered } 1,00,000 \\
\text { tests; cases tolled to } 1,94,504\end{array}$ \\
\hline 8 & 01 June 2020 & 30 June 2020 & 30 & UL1 & $\begin{array}{l}\text { Lockdown only in containment zones; highest } \\
\text { backlog fatalities in Delhi and Maharashtra; new } \\
4,00,000 \text { cases in } 38 \text { days }\end{array}$ \\
\hline 9 & 01 July 2020 & 31 July 2020 & 31 & UL2 & $\begin{array}{l}\text { Announced with more ease in restrictions; } \\
\text { lockdown only in containment zones; crosses } \\
6,00,00 \text { cases }\end{array}$ \\
\hline 10 & 01 August 2020 & 31 August 2020 & 31 & UL3 & $\begin{array}{l}\text { Relaxed night curfews; administered 1,000,000 } \\
\text { tests; Maharashtra and Tamil Nadu imposed } \\
\text { lockdown for a month }\end{array}$ \\
\hline 11 & 01 September 2020 & 30 September 2020 & 30 & UL4 & $\begin{array}{l}\text { Lockdown only in containment zones; reached } \\
1,017,000 \text { cases; limited public gatherings }\end{array}$ \\
\hline 12 & 01 October 2020 & 31 October 2020 & 31 & UL5 & $\begin{array}{l}\text { Lockdown only in containment zones; declined rate } \\
\text { of cases; permitted inter-state movement }\end{array}$ \\
\hline 13 & 01 November 2020 & 30 November 2020 & 30 & UL6 & $\begin{array}{l}\text { No new guidelines; active cases reduced to } \\
4,94,000 \text {; limited public gatherings }\end{array}$ \\
\hline 14 & 01 December 2020 & 15 January 2021 & 46 & UL7 & $\begin{array}{l}\text { Vaccination plan announced; active cases declined } \\
\text { to } 2,14,000 \text {; new coronavirus variant detected }\end{array}$ \\
\hline 15 & 16 January 2021 & 15 February 2021 & 31 & UL8 & $\begin{array}{l}\text { COVID-19 vaccine rollout; active cases declined to } \\
\text { 1,68,000; public transport and gathering restored; } \\
\text { administered } 7 \text { million vaccinations }\end{array}$ \\
\hline 16 & 16 February 2021 & 15 March 2021 & 28 & UL9 & $\begin{array}{l}\text { Total cases 2,19,262; more cases in Maharashtra, } \\
\text { Punjab, Karnataka, Gujarat and Tamil Nadu; } \\
\text { Tamil Nadu extended lockdown; administered } 30 \\
\text { million vaccinations; total of } 158,725 \text { deaths }\end{array}$ \\
\hline 17 & 16 March 2021 & 15 April 2021 & 31 & UL10 & $\begin{array}{l}\text { Surge in daily cases; enforced the Test-Track-Treat } \\
\text { protocol for the second wave; more cases in } \\
\text { Maharashtra, Kerala, Karnataka, Tamil Nadu and } \\
\text { Andhra Pradesh; administered } 100 \text { million vac- } \\
\text { cinations }\end{array}$ \\
\hline
\end{tabular}

(moderate); 201-300 (poor), 301-400 (very poor) and 401500 (severe).

\section{Exceedance factor}

The annual average levels of the air quality parameters were calculated for the chosen cities for the years 2019 and 2020. According to the standards and classes prescribed by the $\mathrm{CPCB}$, the intensity of persistence of the pollutants can be calculated using the exceedance factor (EF), as stated below (CPCB 2016):

$E F=\frac{\text { Pollutant annual mean concentration }}{\text { Annual standard for pollution }}$

The above expression was used to measure the level of pollution for the 12 air quality parameters for the chosen 15 cities. Furthermore, the air pollution status was analysed using 
the following criterion: low pollution (L), $\mathrm{EF}<0.5$; moderate pollution $(\mathrm{M}), \mathrm{EF}=0.5$ to 1.0 ; high pollution $(\mathrm{H}), \mathrm{EF}=1.0$ to 1.5 ; and critical pollution, $\mathrm{EF}>1.5$.

\section{Correlations and trends}

The inter-dependencies and similarities in the observed concentration of air pollutants from the 15 cities invariably proclaimed the existence of complex interactions. In order to evaluate the cross-similarities among the pollutants as well as the locations, various hypotheses were tested using the statistical analysis tool pack available in Microsoft Excel spread sheet. Anticipating the variation of the phase-wise averaged air quality parameters within the sample domain (study period), a null hypothesis is defined for a particular function to ascertain its validity based on the permissible level of significance (invariably taken as 5\% for all cases). Initially, the significance of differing the sampling locations (Tier-I cities and Tier-II cities) versus period of study (phases) for a single pollutant was analysed using two-factor ANOVA without replication. This is performed by defining the hypotheses as follows:

Null hypothesis, $\mathrm{H}_{0}: \mu_{\text {city-1 }}=\mu_{\text {city-2 }}=\ldots \mu_{\text {city-n }}$

Alternate hypothesis, $\mathrm{H}_{1}: \mu_{\text {city-1 }} \neq \mu_{\text {city-2 }} \neq \ldots \mu_{\text {city-n }}$

where $\mu_{\text {city }}$ indicates the mean value of the pollutant in all the cities (6 Tier-I cities and 9 Tier-II cities) during the selected phase period. This is repeatedly performed for all the remaining pollutants.

In a similar way, the resemblance of having significant variation for different pollutants for a particular city was tested using the principles of ANOVA as follows:

Null hypothesis, $\mathrm{H}_{0}: \mu_{\text {pollutant- } 1}=\mu_{\text {pollutant- } 2}=\ldots \mu_{\text {pollutant-n }}$

Alternate hypothesis, $\mathrm{H}_{1}$

$$
: \mu_{\text {pollutant-1 }} \neq \mu_{\text {pollutant-2 }} \neq \ldots \mu_{\text {pollutant-n }}
$$

where $\mu_{\text {pollutant }}$ indicates the mean value of the pollutants in a particular city during the selected phase period. This is also performed repeatedly for all the remaining cities.

The significance of considering AQI as a unique parameter for the air pollution based on the same standard limits in both Tier-I and Tier-II cities is evaluated by employing $t$-tests. The hypotheses are defined as follows:

Null hypothesis, $\mathrm{H}_{0}: \mu_{\text {pollutant-1 }}=\mu_{\mathrm{AQI}}$

Alternate hypothesis, $\mathrm{H}_{1}: \mu_{\text {pollutant-1 }} \neq \mu_{\mathrm{AQI}}$

where $\mu_{\text {pollutant- } 1}$ indicates the true mean of a pollutant for a city and $\mu_{\mathrm{AQI}}$ indicates the comparison value of the corresponding AQI.
As mentioned earlier, in order to compare the significance of availing different durations while defining the BDL phase, another set of $t$-tests was performed by keeping the average value obtained for BDL-1 as the reference for pre-lockdown period. This test also serves as a comparison of pollution trends during different lockdown and unlocking phases compared to the pre-lockdown scenario.

Finally, the correlation between air pollution and the prevailing spread of COVID-19 pandemic was evaluated by considering the AQI as the sole representative of air pollution scenario and by configuring the COVID-19 infection levels into four classes, namely confirmed cases, active cases, deceased cases and recovered cases. The correlation analysis particularly included the entire history of COVID-19 spread and its after-effects in India, starting from the onset, spike, drop and also the symptoms of the next phase onset. In addition, this correlation is included with the early-stage history of administered vaccinations during the last 3 months of the study (January 16, 2021, to April 15, 2021). The required daily distribution datasets were prepared by converting the cumulative dataset for COVID-19 (mass curve) in order to highlight the transformations that happened during each phase of the study period. Furthermore, in order to normalize the data among each cities of unique gesture, three additional parameters were defined to effectively represent the statistical impacts of COVID-19 on public health.

Active ratio

$$
\begin{aligned}
= & \frac{\text { no. of active cases during selected time period }}{\text { no.of confirmed cases during same period }} \\
& \times 100
\end{aligned}
$$

Recovery ratio

$$
\begin{aligned}
= & \frac{\text { no. of recovered cases during selected time period }}{\text { no.of confirmed cases during same period }} \\
& \times 100
\end{aligned}
$$

Case fatality ratio

$$
\begin{aligned}
= & \frac{\text { no. of deceased cases during selected time period }}{\text { no.of confirmed cases during same period }} \\
& \times 100
\end{aligned}
$$

\section{Results and discussion}

\section{Status of air pollution responses}

Apart from many isolated case studies of air quality variations, the results of the present study unveil a 
comprehensive overview of the spatiotemporal variations of 12 major air pollutants across the 15 Indian cities including Tier-I and Tier-II cities. The details of the phase-wise averaged distributions of the air pollutants are provided in Table 6 . It can be inferred that there is a common trend of declining concentrations for all major air pollutants during various phases in 2020 compared to 2019; nonetheless, a mere generalization would be incomplete without referring to the specific attributes of the location. For example, based on the results for Tier-I cities, the highest percentage of reduction in Chennai city was observed for $\mathrm{PM}_{10}$, followed by $\mathrm{PM}_{2.5}$ and toluene, while the reduction in the city of Delhi was highest for $\mathrm{NO}_{x}$ followed by $\mathrm{PM}_{2.5}$ (Fig. 2a-e). Despite clear deviation from the historic trends, the highest reduction was observed during the middle stages of lockdown (LD2 and LD3). The highest degree of reduction in Mumbai city was reported for $\mathrm{CO}$ followed by $\mathrm{NO}_{x}$ and $\mathrm{PM}_{10}$ which is similar to Bengaluru. Similarly, Kolkata and Hyderabad have the highest reduction in $\mathrm{PM}_{2.5}$ and $\mathrm{PM}_{10}$. In a similar way, significant variations in air quality were observed for Tier-II cities also. One can observe a striking similarity in the concentration trends for the coastal cities despite being classified under different tiers. It is also observed that the concentrations of a few gaseous pollutants such as $\mathrm{O}_{3}, \mathrm{NH}_{3}$ and petroleum hydrocarbons were increasing during the lockdown phases, especially for the south Indian cities. As reported in a few previous studies (Pant et al. 2020; Gautam et al. 2020), such anomalies can be more preferably related to the human activities than to the local weather conditions.

As evident from the graphs (Fig. 2a-e), some pollutants take a longer time to decrease from their higher values during BLD3 as indicated by the negative values of reduction (which means increase). This is partially due to the impact of considering BLD3 as the reference for estimating reduction in concentration as compared to 2019, which is an averaged value over 449 days prior to the first lockdown. Therefore, the results may substantiate the healing effect of long-term averaging studies despite the necessity to identify the extent of anomalies, which is useful in making futuristic predictions (Ropkins and Tate 2021). However, it is also anticipated that the existence of already released emissions in the atmosphere may be experienced for a longer period even after imposing the sudden lockdowns and may be reduced eventually if such restrictions are continually followed.

Based on the results, it may seem to revisit the assumption that the reduction in air pollution was only a phenomenal consequence during the lockdowns, as the trends started reversing while the government of India announced partial unlocking phases during the later period. Except for Hyderabad and Bengaluru, almost all cities have regained increased emissions of pollutants during the unlocking phases, primarily due to the increased transportation activities. Phenomenal increase or decrease in pollutant concentrations during these phases can also be attributed to the regulatory infrastructure followed by the individual state governments as ordained by the central government. Since this particular study is focused on the early impacts of lockdown and unlocking phases, and is also based on a long-term averaged reference, the results safely provide strong evidence for further analysis of air quality during the later unlocking periods to extrapolate the anticipated trend.

\section{Variation in exceedance factor and AQI}

As mentioned above, the AQI is a summative figure of the prevalence of all major air pollutants for a given location and period. In order to capture the similarity of the means, the distributions of AQI as well as each pollutant need to be compared between 2019 and 2020 . It is observed that the occurrence of anomalies in pollutant concentrations on a yearly basis can be effectively described using the exceedance factor (EF). The results from the current study show that there is a clear relationship between the percentage variation in AQI (during 2019-2020) and the observed range of EF values (Fig. 3). When compared to the previous graphs, there is a significant reduction in pollutant concentrations as depicted by the EF scores during 2019-2020 for all Indian cities despite the fact that the range of EF is closely associated with the pollution history. This may be due to the fact that EF is calculated based on the yearly average value for a particular pollutant whereas the AQI is calculated based on the worst case scenario within the selected timeframe of analysis (Roy and Singha 2020). It is evident from the fact that though there are reductions in EF scores, majority of the cities are exhibiting increased pollution deviating from the national ambient air quality standards (NAAQS) set in force by the CPCB especially during the early unlock phases. This is clearly observed in the case of $\mathrm{PM}_{2.5}, \mathrm{PM}_{10}$ and $\mathrm{CO}$ (Fig. 3) indicating the lack of adequate enforcement infrastructure to improve the urban air quality in many Indian cities which can cause terrific disasters while handling any airborne pandemic as we see in the following sections. The variation in annual AQI thus serves as a reference to identify the cities whose variations are quite significant based on the short-term averaging techniques. 

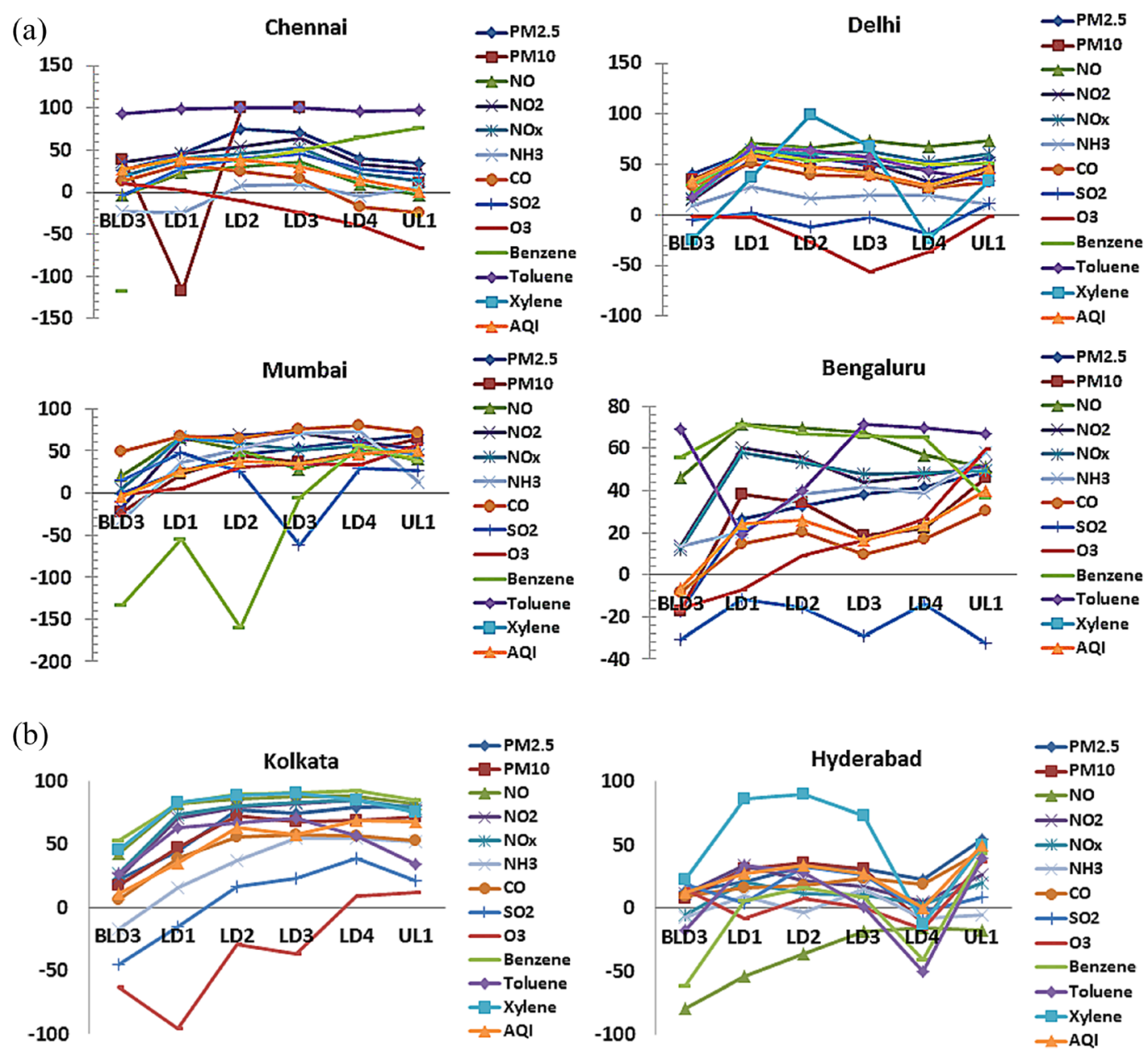

$$
\begin{aligned}
& \sim \text { PM2.5 } \\
& -\mathrm{PM} 10 \\
& -\mathrm{NO} \\
& \leftarrow \mathrm{NO2} \\
& -\mathrm{NOx} \\
& -\mathrm{NH3} \\
& -\mathrm{CO} \\
& +\mathrm{SO} 2 \\
& -\mathrm{O} 3 \\
& - \text { Benzene } \\
& \sim \text { Toluene } \\
& - \text { Xylene } \\
& - \text { AQI }
\end{aligned}
$$

(c)
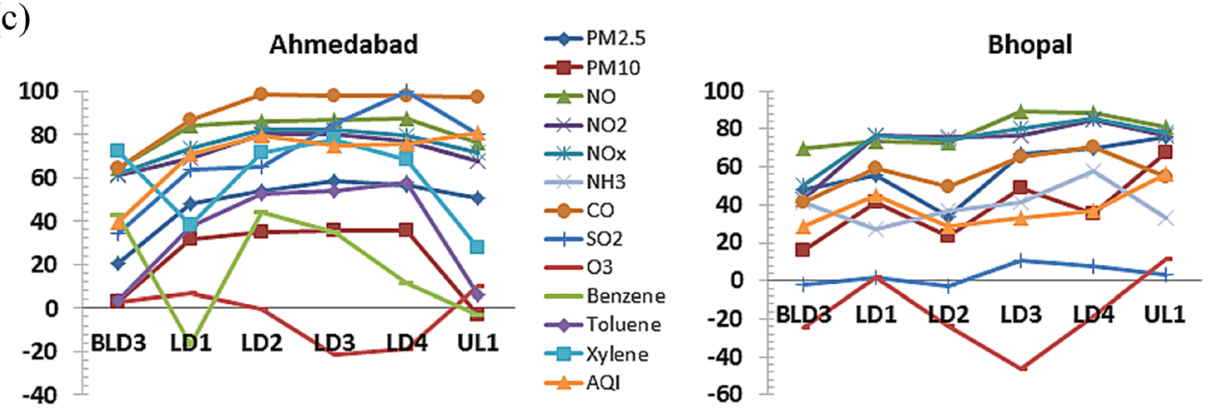

$$
\begin{aligned}
& \leadsto \text { PM2.5 } \\
& \rightarrow \mathrm{NO} \\
& \leftarrow \text { NO2 } \\
& \text { *NOX } \\
& \because \mathrm{NH} 3 \\
& \text {-CO } \\
& +\mathrm{SO} 2 \\
& \text { - Benzene } \\
& \leadsto \text {-Toluene } \\
& - \text {-Xylene } \\
& -\mathrm{AQI}
\end{aligned}
$$

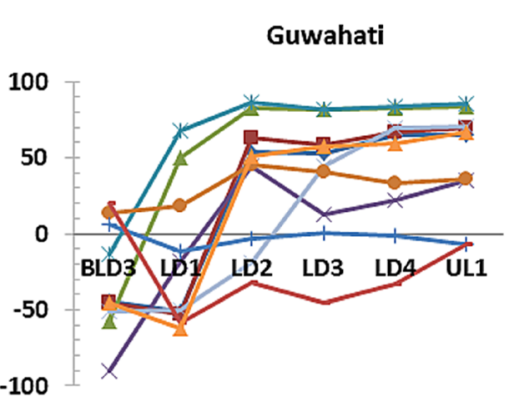

$\rightarrow-$ Xylene $\quad-100$

Fig. 2 Trend of air quality parameters and AQI for Tier I and Tier II cities during pre-lockdown, lockdown and unlock phases 

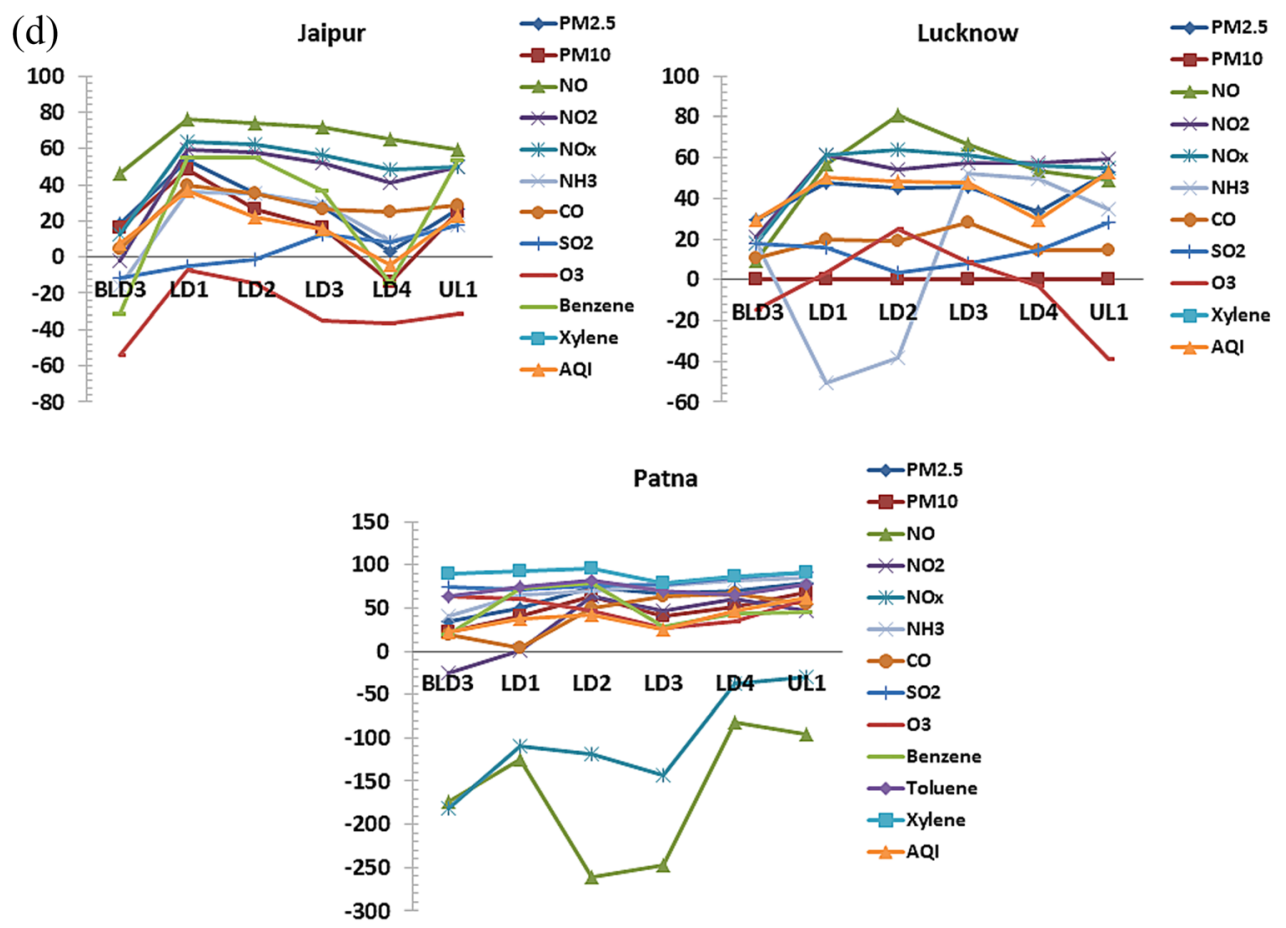

(e)
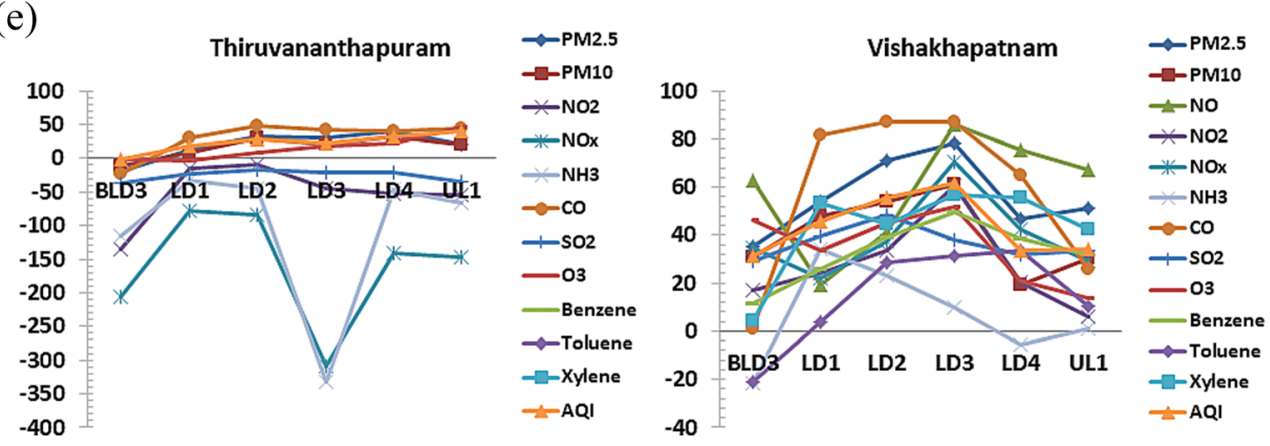

Fig. 2 (continued)

\section{Spatiotemporal trend analysis of AQI with its core elements}

In addition to the bulk analysis, the specific trends of individual parameters were also evaluated to understand their variability among the locations (cities) and the time periods (phases). The key results from the two-factor ANOVA (without replication) were expressed in terms of $F$ value and $p$ value. Based on the validity of the null hypothesis to justify the test statistic, only pollutant-wise ANOVA tests were satisfactorily performed for both Tier-I and Tier-II cities independently (Table 4$)$. The $F$ critical values $\left(F_{\text {crit }}\right)$ were obtained for each of the tests when the level of significance $(\alpha)$ was set to be 0.05 . The null hypothesis was rejected when the resulting $p$ value is less than the $\alpha$ value, as well as the resulting $F$ value is greater than the obtained $F_{\text {crit }}$ values. The $F_{\text {crit }}$ values for Tier-I cities are found to be 2.285 and
2.485 while testing the variability among the time periods and cities respectively.

The phase-averaged AQI values have shown significant variations for both Tier-I and Tier-II cities when the time period and location of cities were considered the preferred sources of variation. Out of the 12 parameters, a statistically significant similarity in the average values of pollutant concentrations was observed for $\mathrm{SO}_{2}, \mathrm{O}_{3}$, benzene and xylene during different phases of the study while all other pollutants showed significant variations. However, there was no case of $p$ value exceeding the $\alpha$ value for various cities, thus ensuring the distinct distribution of air pollutants in Tier-I cities. The results are further confirmed with the higher $F$ values exceeding the $F_{\text {crit }}$ values. In the case of Tier-II cities, majority of the pollutants exhibited significantly differing average concentrations over the selected time periods, except for $\mathrm{CO}, \mathrm{SO}_{2}, \mathrm{O}_{3}$, benzene and xylene. 

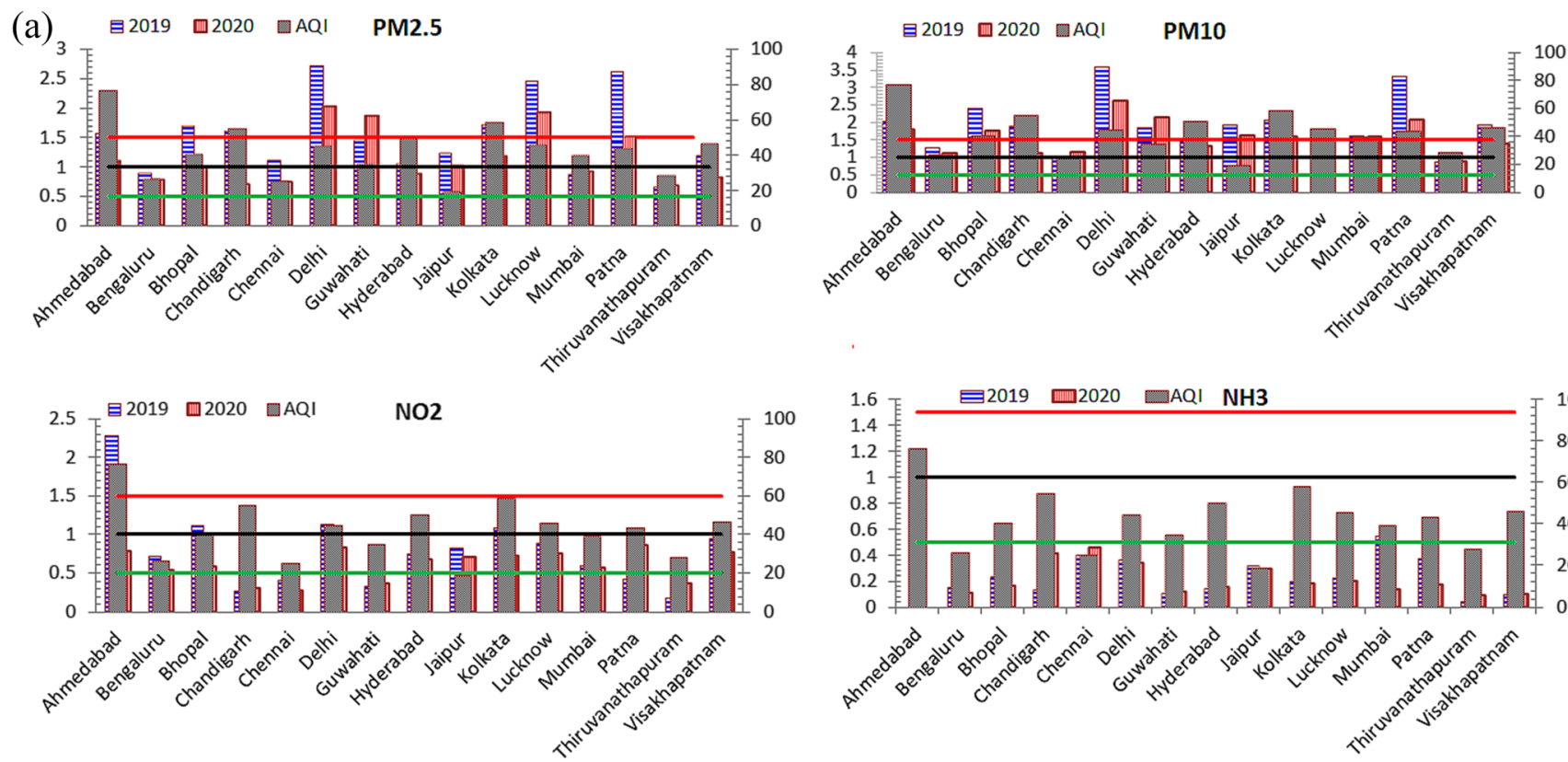

(b)
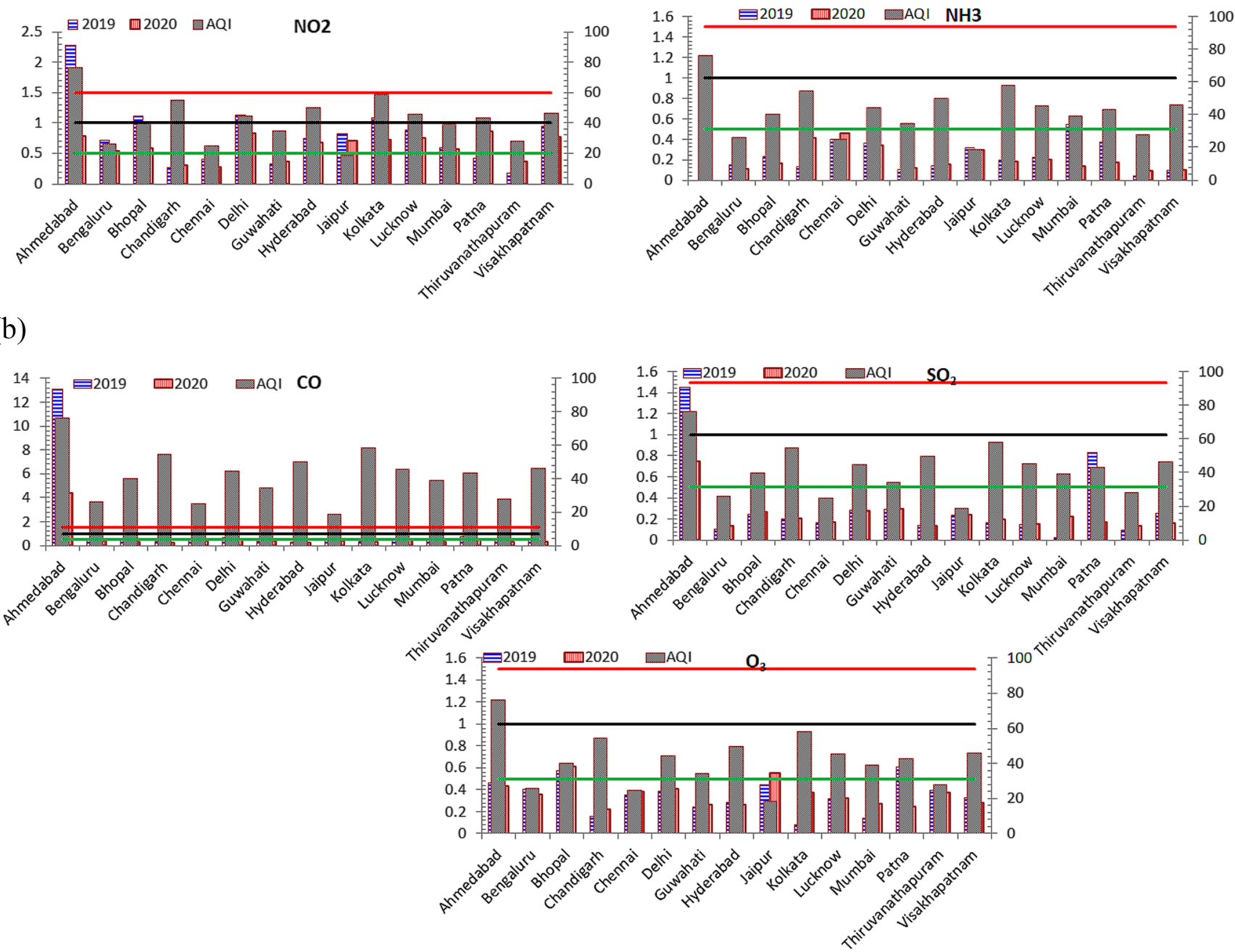

Fig. 3 Percentage variation in AQI and Exceedance factor values for Tier I and Tier II cities during 2019 and 2020

This indicates some kind of delay in pollutant abatement from the atmosphere in response to the imposed lockdown schedule which is in coherence with the observation mentioned above regarding the selection of short-term averaging techniques. Apart from the meteorological and geographical contributions, it is also to be understood from the public media that the enforced strict COVID-19 protocols were not uniform among the various Indian states despite the official announcements (Table 3). This is confirmed from the $p$ values and $F$ values for the pollutants among the nine Tier-II cities. Hence, the trend analysis serves as a preferable technique to obtain the level of significance of pollutant concentrations in the atmosphere under multiple sources of variations.

In order to understand the significance of variation in the selected air pollutants due to the difference in time scale of reference, two-tailed $t$-tests were performed by 
Table 4 Trend analysis for various air quality parameters based on the ANOVA tests

\begin{tabular}{|c|c|c|c|c|c|}
\hline \multirow[b]{2}{*}{ Air Quality Parameter } & \multirow[b]{2}{*}{ Variability } & \multicolumn{2}{|c|}{ Tier-I cities } & \multicolumn{2}{|c|}{ Tier-II cities } \\
\hline & & $\mathrm{F}$ value & $\mathrm{p}$-value & F value & p-value \\
\hline \multirow[t]{2}{*}{ AQI } & Time periods & $6.9583^{\$}$ & $3.28 \mathrm{E}-05^{*}$ & $5.9454^{\ddagger}$ & $3.38 \mathrm{E}-05^{*}$ \\
\hline & Cities & $12.7572^{\#}$ & 4.31E-07 & $7.3491^{\phi}$ & $1.25 \mathrm{E}-06$ \\
\hline \multirow[t]{2}{*}{ PM2.5 } & Time periods & 11.2645 & $2.25 \mathrm{E}-07$ & 12.0757 & $2.80 \mathrm{E}-09$ \\
\hline & Cities & 14.6850 & $9.01 \mathrm{E}-08$ & 8.9936 & 7.77E-08 \\
\hline \multirow[t]{2}{*}{ PM10 } & Time periods & 3.9523 & 0.0028 & 5.31048 & 0.0001 \\
\hline & Cities & 6.6195 & 0.0002 & 14.1976 & $4.78 \mathrm{E}-11$ \\
\hline \multirow[t]{2}{*}{ NO } & Time periods & 5.6833 & 0.0002 & 2.3265 & 0.03715 \\
\hline & Cities & 8.6366 & $2.08 \mathrm{E}-05$ & 22.7064 & $5.49 \mathrm{E}-15$ \\
\hline \multirow[t]{2}{*}{$\mathrm{NO} 2$} & Time periods & 12.1791 & $9.10 \mathrm{E}-08$ & 8.0715 & $9.30 \mathrm{E}-07$ \\
\hline & Cities & 10.0612 & 4.95E-06 & 7.3132 & $1.33 \mathrm{E}-06$ \\
\hline \multirow[t]{2}{*}{ NOx } & Time periods & 8.4660 & 4.90E-06 & 6.4216 & $1.46 \mathrm{E}-05$ \\
\hline & Cities & 5.3783 & 0.0009 & 8.7744 & $1.11 \mathrm{E}-07$ \\
\hline \multirow[t]{2}{*}{ NH3 } & Time periods & 8.4262 & $5.14 \mathrm{E}-06$ & 2.2532 & 0.0430 \\
\hline & Cities & 118.4700 & $6.53 \mathrm{E}-21$ & 17.7179 & $7.86 \mathrm{E}-13$ \\
\hline \multirow[t]{2}{*}{$\mathrm{CO}$} & Time periods & 5.6522 & 0.0002 & 1.4289 & 0.2122 \\
\hline & Cities & 11.6691 & $1.11 \mathrm{E}-06$ & 3.9135 & 0.0010 \\
\hline \multirow[t]{2}{*}{$\mathrm{SO} 2$} & Time periods & 0.8898 & 0.5249 & 1.9054 & 0.0858 \\
\hline & Cities & 13.2505 & $2.85 \mathrm{E}-07$ & 5.9351 & $1.68 \mathrm{E}-05$ \\
\hline \multirow[t]{2}{*}{$\mathrm{O} 3$} & Time periods & 0.7255 & 0.6514 & 1.1075 & 0.3714 \\
\hline & Cities & 5.6978 & 0.0006 & 19.6397 & $1.05 \mathrm{E}-13$ \\
\hline \multirow[t]{2}{*}{ Benzene } & Time periods & 1.6227 & 0.1615 & 0.6747 & 0.6925 \\
\hline & Cities & 4.5886 & 0.0025 & 14.9410 & $1.91 \mathrm{E}-11$ \\
\hline \multirow[t]{2}{*}{ Toluene } & Time periods & 2.4884 & 0.0348 & 2.4580 & 0.0285 \\
\hline & Cities & 25.9983 & 7.17E-11 & 36.7694 & $1.39 \mathrm{E}-19$ \\
\hline \multirow[t]{2}{*}{ Xylene } & Time periods & 2.1694 & 0.0615 & 1.9389 & 0.0804 \\
\hline & Cities & 9.0741 & $1.32 \mathrm{E}-05$ & 5.5764 & $3.35 \mathrm{E}-05$ \\
\hline
\end{tabular}

$\$$ : $F$ value corresponding to the $F$-critical value ( $F$ crit $=2.285)$; $\#$ : $F$ value corresponding to the $F$-critical value $(F$ crit $=2.485)$; * $p$-value corresponding to the level of significance $(\alpha=0.05)$; $¥ \mathrm{~F}$ value corresponding to the $\mathrm{F}$-critical value (Fcrit $=2.178$ ); $\not$ : F value corresponding to the F-critical value (Fcrit $=2.108)$

comparing the true means for the various phases of lockdown series (LDS) while considering BLD1 as the comparison mean (representative of pre-lockdown period from January 01,2019$)$. For the preferred $\alpha$ value of $5 \%$, the observed levels of significance ( $p$ values) were quite low for majority of the pollutants in Tier-I cities. The highest impact of lockdown was observed in the concentrations of $\mathrm{NO}_{x}$ and $\mathrm{PM}_{2.5}$ in majority of the Tier-I cities. Two distinguishing features of the Tier-I cities to cause this deviation are ascertained to be the reduced vehicular emissions caused by the decrease in public transport and climatic modifications in the coastal cities during the study period. On the other hand, majority of the Tier-II cities did not exhibit any significant difference for the averaged pollutant concentrations as a consequence of restrictions imposed during the LDS except in the case of
$\mathrm{PM}_{2.5}$ and $\mathrm{CO}$ concentrations. One reason for this phenomenon may be attributed to the lesser impact of reduced vehicular emissions compared to the partially continued industrial activities. Based on the trend analysis, it is observed that consideration of long-term averaging techniques as the reference for measuring the impacts of short-term LDS can give significant insights to the cause of pollution incidents and the effectiveness of their control strategies.

\section{Was air pollution a precursor in extending COVID-19 impacts?}

Being the second most populated country in the world, India has been valiantly fighting against the COVID-19 spread, in spite of the projected historical ambiguities 
persisting while pursuing the environmental quality norms. Considering the infrastructural limitations in handling the serious consequences of pandemic situations, India had exhibited strong political strategies during the onset period of COVID-19 by announcing the country's longest-ever lockdown series during March-May 2019. In order to keep the population safe and moving, individual states have taken various preparatory steps including uninterrupted emergency services to get the maximum benefits of complete lockdown. Therefore, it is important to investigate the correlations and trends of COVID-19 issues and the prevailing air quality while implementing such massive institutional restrictions. In order to make the comparison more generic and informative, the phase-averaged AQI values were computed for the entire period of COVID-19 pandemic (including 4 lockdown events and 10 unlock events until April 2021). Similarly, the COVID-19 database is represented with five critical parameters, namely positive confirmed cases, deceased cases, active cases, recovered cases and vaccination cases (expressed as actual count).

The results from the two-way ANOVA studies among these counts and the corresponding AQI values revealed that air quality can be an important precursor to estimate the critical phase of COVID-19 spread and the effectiveness of control measures taken during that period. The prepared databases of the phase-averaged counts and AQI values are presented in Table 7. It is observed that each phase of the study period was characterized by certain temporary activities including establishment of containment zones and red zones in various parts of the cities (Table 2). The results indicate that gradual relaxations of the restrictions during the later stages have enabled increased pollution activities and have worsened the air quality in many cities.

Another important activity to curtail the pandemic spread was the introduction of vaccine from January 16, 2021. Thereafter, the country has witnessed massive spikes in the vaccination doses through large-scale vaccination drives. As evident from the trend analysis results, the later stages of unlocking were illustrating a reversal of earlier trends of disease spread, an indication of the popular phrase "COVID wave." This is associated with a combination of mutually exclusive events such as administration of massive vaccination drives while granting permission to hold local gatherings. As a result, the correlation analysis showed that there is no significant trend and correlation between AQI and COVID-19 database for Tier-I cities except for the vaccination cases and recovery cases (Fig. $4 \mathrm{a}-\mathrm{c}$ ).

In addition, it also observed that the COVID-19 impact parameters such as active ratio, recovery ratio and case fatality ratio do not hold the same relationship with the AQI values as compared to their parent components (actual counts). The correlation between AQI and recovery ratio was found to be positive and significant (between 0.35 and 0.55 ) for all Tier-I cities except for Chennai (Fig. 5a). It is to be noted that Chennai, Bengaluru and Hyderabad are the cities with better air quality (i.e. lower AQI values) compared to the other three cities in the same group, and have experienced drastic variations in AQI during the lockdown and unlocking periods. This variability has caused these cities to limit almost all their correlations with COVID-19 parameters to be something less than $50 \%$. Another remarkable observation is that three biggest metropolitan cities-Delhi, Mumbai and Kolkata-showed highest correlation for AQI with vaccine data but in the negative direction. This can be attributed to the onset of second wave, showing further rapid increase in the positive confirmed cases, despite increase in the vaccination cases (Link 8 (2021)).

The results also facilitate another discussion on the consequence of imposing initial lockdown series as against administering vaccinations, as both were introduced at a critical juncture to curtail the possibility of community spread. In the present study, both these trials have the same duration of 3 months, thus making it more comparable. As evident from the study, the lockdown phases were crucial in limiting the active ratio and recovery ratio by enabling institutionalized implementation of public health precautions such as social distancing and wearing masks. The results also indicate that case fatality ratio has drastically reduced during the initial 3 months of vaccination dosage. However, this is not sufficient to declare that vaccination alone can stop spreading the pandemic despite seeing the current evidences of the next phase spread.

Comparing the results of correlation analysis for the Tier-II cities, it is observed that the confirmed cases, recovery cases and vaccination cases bear significant correlation with AQI (always greater than 30\%) except for Patna and Lucknow (Fig. 5b, c). Highest negative correlation was observed for vaccination cases (always greater than 40\%) except for Patna and Jaipur. The low correlation between AQI and COVID-19 data in those cities may be attributed to the exceptionally high records of AQI values as a remark of their pollution history. This is verified based on the pre-lockdown data analysed presented in Table 3 . It is also important to note that the correlation of AQI with active cases remains very poor in almost all cities with negative values for Pearson's product moment correlation coefficient. This is due to the rapid variations in the number of daily active cases causing irregular increases and decreases compared to the previous phase values. 
Based on the available medical records, the variations in the case fatality ratio may be mainly caused by the infection by the novel coronavirus instigating other prominent health issues like cardinal attack, pneumonia and other types of lung infections (Balakrishnan et al. 2014; Gorbalenya et al. 2020). However, the correlation analysis strongly substantiates the necessity to investigate the possibility of associated air pollution history to worsen the scenario causing such high casualty records. This can be further enlightened by including the meteorological, social and institutional factors also into consideration. Actually, most of the present results are mainly aimed to provide a feasibility analysis to correlate these factors; and therefore, we feel that the linear correlations may not fit well to predict the cyclic (or wave-type) nature of the daily record of COVID-19 database for Indian scenario. We therefore strongly recommend using multi-criteria non-linear correlation analysis to reveal more about the hidden interactions in our understanding about the atmospheric reach of coronavirus and its associated health risks.
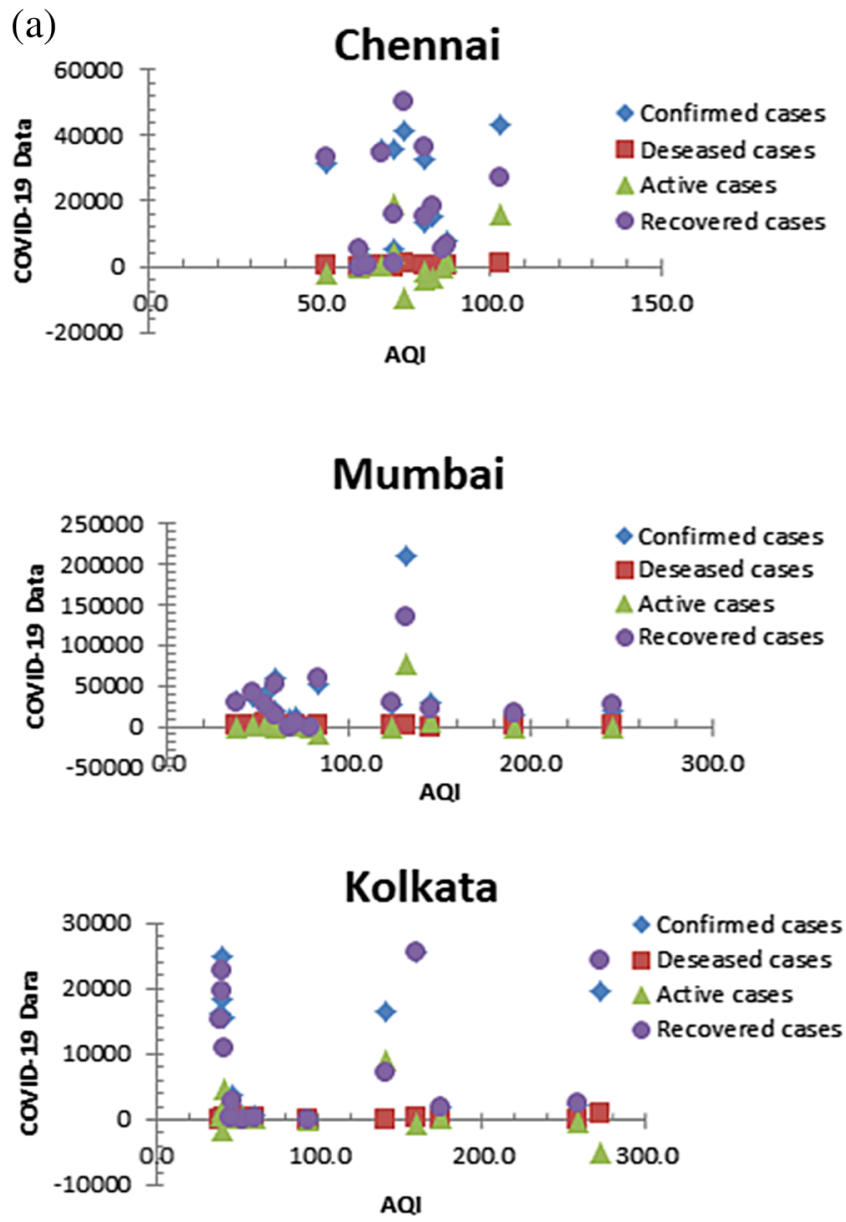

\section{Proposed classification based on significance of responsiveness}

Considering the outreach of the COVID-19 pandemic in redefining the global socio-economic margins, it is necessary to have city-specific strategic plans to combat the widespread impacts and associated public health risks. In this regard, the current study postulates a proposal to classify the Indian cities according to their resilience and susceptibility to incorporate sudden impacts of institutionalized massive restrictions in terms of atmospheric quality within their premises. We have observed that quite a few cities are highly responsive and can reflect the significant variations in the concentrations of many air pollutants as a result of the imposed lockdown series, compared to their past historical records.

Based on the results, it is clear that some of the primary air pollutants are widely present in all cities and have minimum diurnal variations across the seasons due to the continuous presence of the interactive sources. However, the lockdown series have clearly
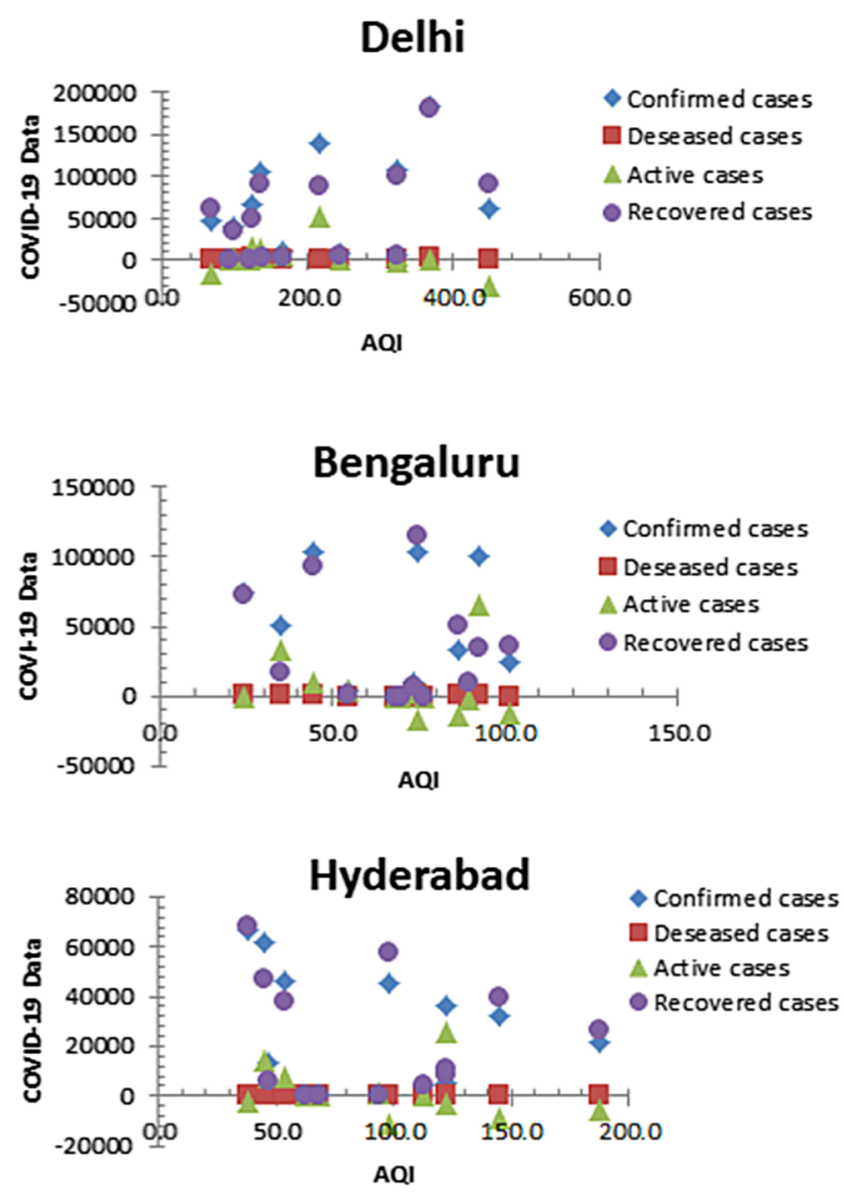

Fig. 4 Correlation between AQI and COVID-19 cases (Confirmed, Deceased, Active, Recovered) 

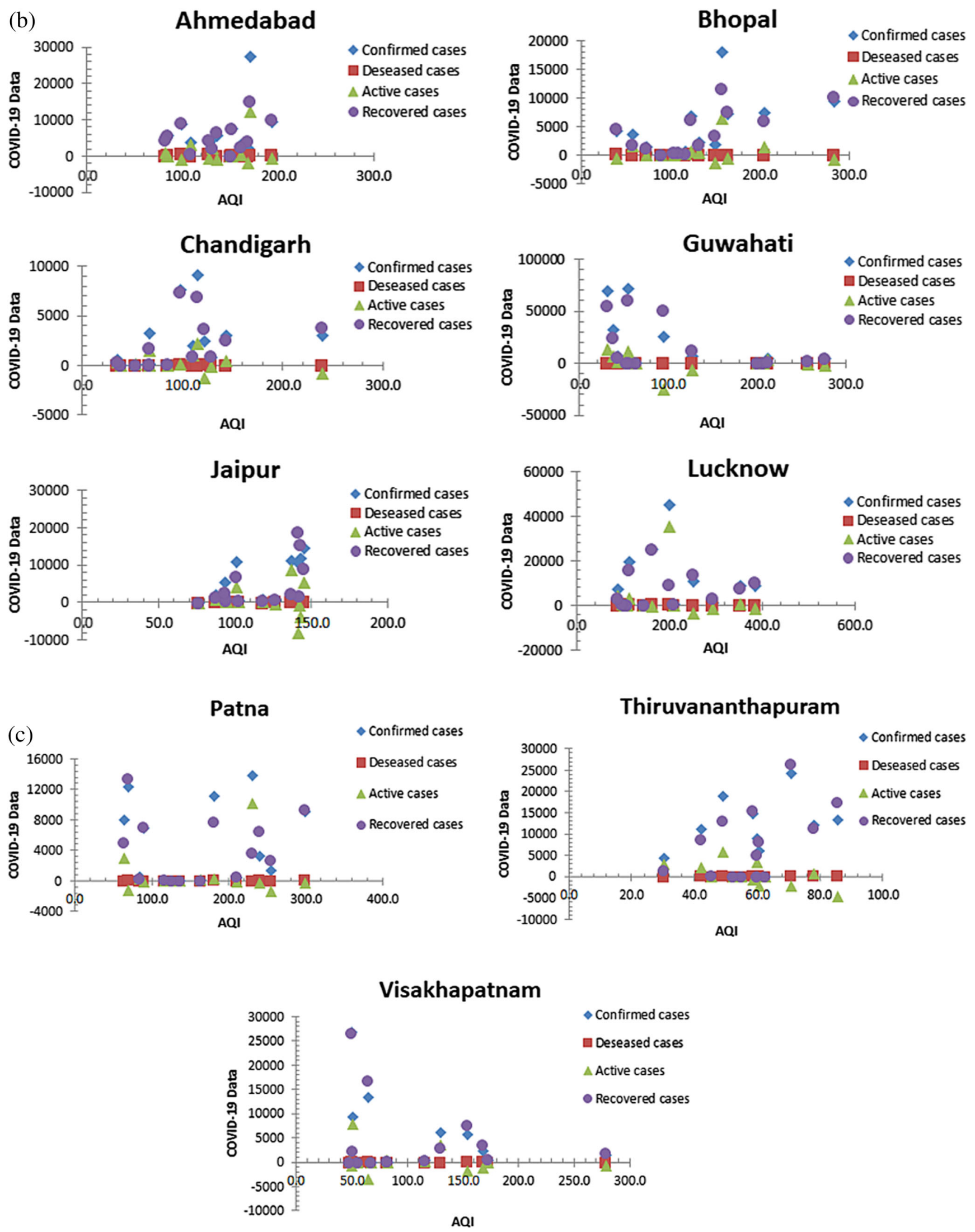

Fig. 4 (continued) 
posed a check on them; and as a result, many cities have shown dramatic changes in their concentrations. Considering these aspects of responsiveness (or in other words, absence of resilience), we have ranked the Indian cities within the Tier-I and Tier-II classifications (Table 5). Among the Tier-I cities, Kolkata stands first followed by Mumbai, Bengaluru and Chennai. This indicates that these cities have experienced a sudden change in the concentrations of the primary air pollutants during the LDS. It is not surprising to see that Delhi comes in the fifth rank because of the persisting air pollution incidents in the city which could not recognize any significant improvements to the short-term activities based on the previous year observations. This is more specifically depicted by the less significant change in AQI compared to BDL1 as the reference. (a)
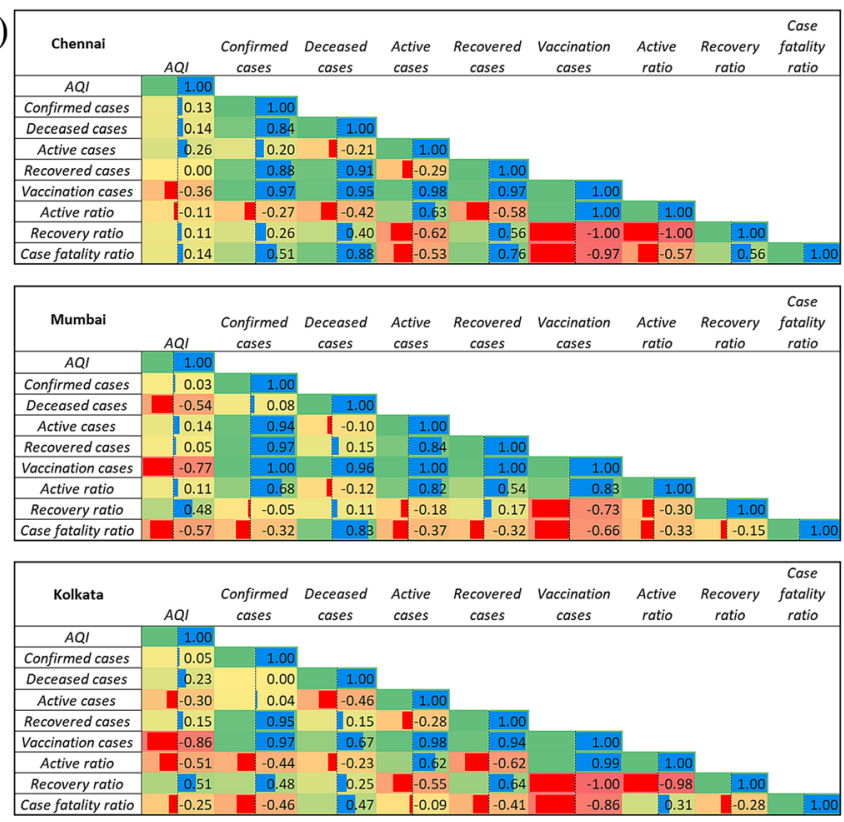
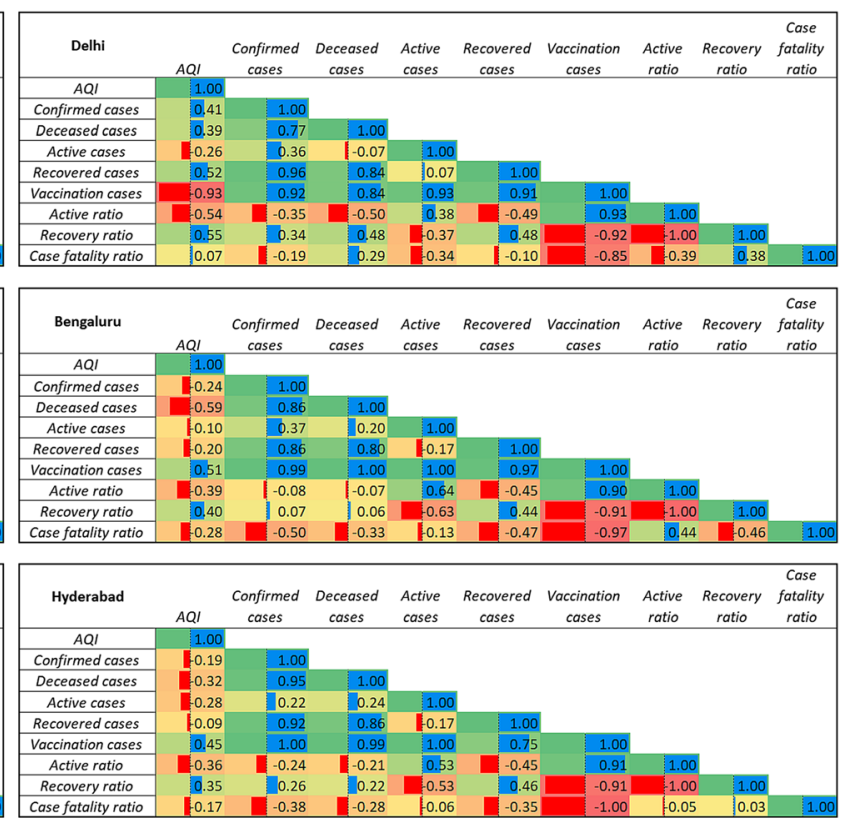

(b)
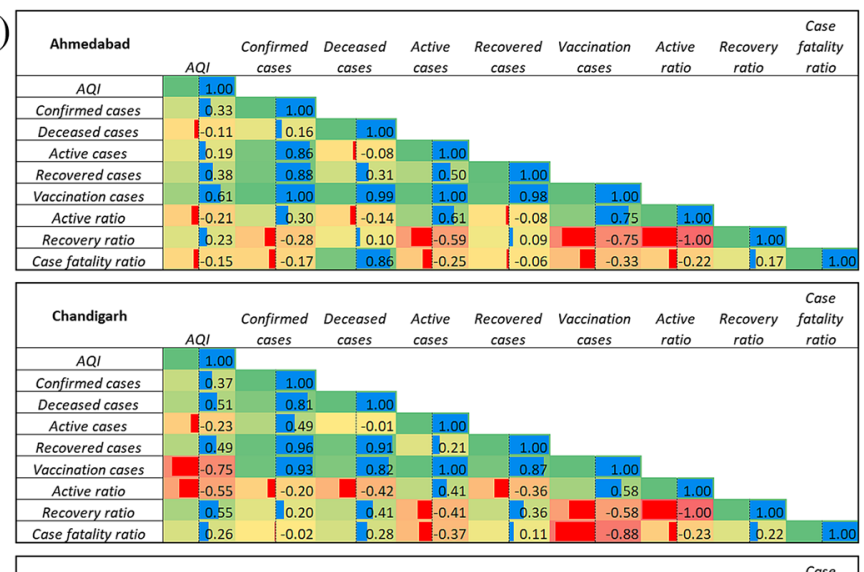
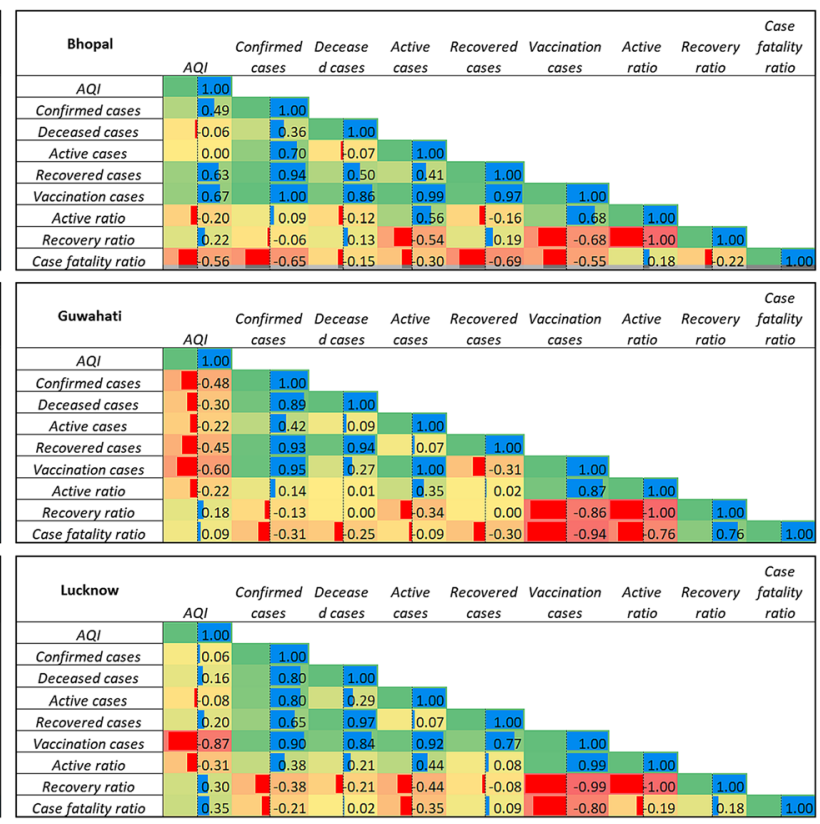

Fig. 5 Correlation between AQI, confirmed cases, deceased cases, active cases, recovered cases, vaccinated cases, active ratio, recovery ration and case fatality ratio 
(c)
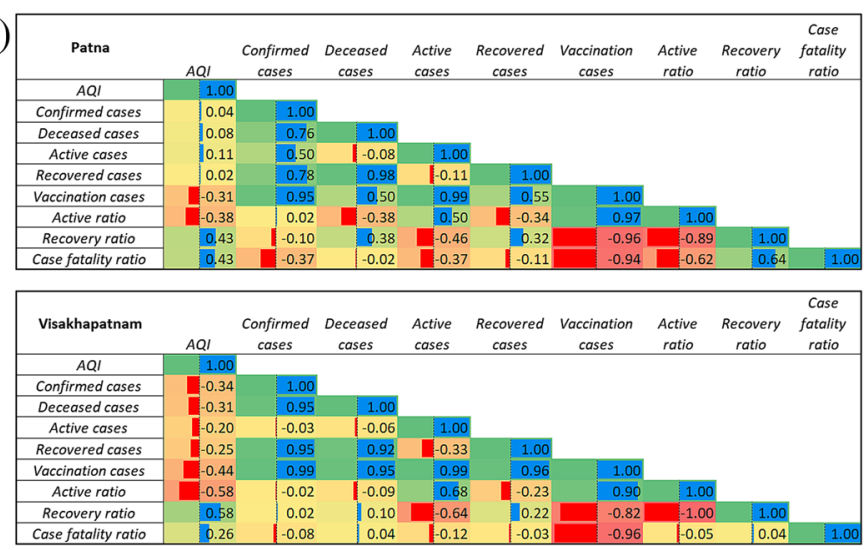

Fig. 5 (continued)

Among the Tier-II cities, the top three ranks are allocated to Patna, Chandigarh and Visakhapatnam, followed by Thiruvananthapuram, Ahmedabad and Bhopal. It is invariably anticipated that curtailing the industrial activities in the Tier-II Indian cities may provide significant improvement in the total environment, which are to be implemented along with reduced public movement. This also points out towards the success of local enforcement activities towards bringing a significant change in the air quality as seen in the modifications in the AQI values. However, caution should be

Table 5 Classification of Tier-I and Tier-II Indian cities according to the significance of their responsiveness to the lockdown events

\begin{tabular}{|c|c|c|}
\hline Location & Significantly varied pollutants & Rank \\
\hline \multicolumn{3}{|l|}{ Tier-I cities } \\
\hline Kolkata & $\mathrm{PM}_{2.5}, \mathrm{PM}_{10}, \mathrm{NO}_{2}, \mathrm{NO}_{x}, \mathrm{NH}_{3}, \mathrm{CO}$ & 1 \\
\hline Mumbai & $\mathrm{PM}_{10}, \mathrm{NO}, \mathrm{NO}_{2}, \mathrm{NO}_{x}, \mathrm{NH}_{3}, \mathrm{O}_{3}$ & 2 \\
\hline Bengaluru & $\mathrm{PM}_{2.5}, \mathrm{PM}_{10}, \mathrm{NO}_{2}, \mathrm{NH}_{3}, \mathrm{CO}$ & 3 \\
\hline Chennai & $\mathrm{PM}_{2.5}, \mathrm{NO}, \mathrm{NO}_{x}, \mathrm{O}_{3}$ & 4 \\
\hline Delhi & $\mathrm{NO}, \mathrm{NO}_{x}$, benzene, toluene & 5 \\
\hline Hyderabad & $\mathrm{PM}_{2.5}, \mathrm{CO}$ & 6 \\
\hline \multicolumn{3}{|l|}{ Tier-II cities } \\
\hline Patna & $\mathrm{PM}_{2.5}, \mathrm{PM}_{10}, \mathrm{NO}_{2}, \mathrm{NH}_{3}, \mathrm{CO}$, benzene & 1 \\
\hline Chandigarh & $\mathrm{NO}, \mathrm{NO}_{x}, \mathrm{CO}, \mathrm{O}_{3}$, benzene & 2 \\
\hline Visakhapatnam & $\mathrm{PM}_{2.5}, \mathrm{NH}_{3}, \mathrm{CO}$, benzene, toluene & 3 \\
\hline Thiruvananthapuram & $\mathrm{PM}_{2.5}, \mathrm{PM}_{10}, \mathrm{CO}, \mathrm{O}_{3}$ & 4 \\
\hline Ahmedabad & $\mathrm{PM}_{2.5}, \mathrm{PM}_{10}, \mathrm{SO}_{2}$, toluene & 5 \\
\hline Bhopal & $\mathrm{PM}_{10}, \mathrm{NO}_{2}$ & 6 \\
\hline Lucknow & $\mathrm{NO}, \mathrm{NO}_{x}$ & 7 \\
\hline Jaipur & $\mathrm{NO}_{2}, \mathrm{NH}_{3}$ & 8 \\
\hline Guwahati & $\mathrm{O}_{3}$ & 9 \\
\hline
\end{tabular}

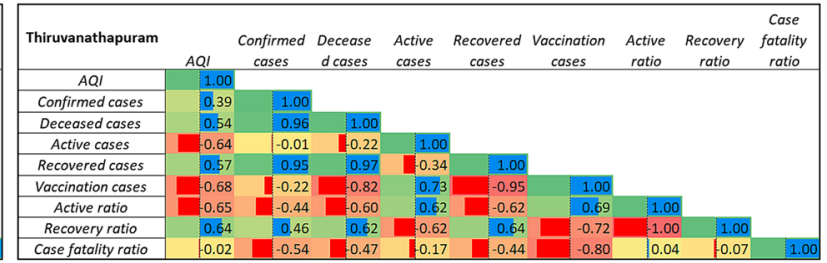

taken while interpreting the reasons for lesser significant changes in air pollutants in Lucknow, Jaipur and Guwahati as they typically represent varying topographical, industrial and climatic conditions. As we observed for Delhi, the cities of Lucknow and Jaipur have shown significant variations for $\mathrm{NO}$ and $\mathrm{NO}_{x}$ concentrations alone, while Guwahati has shown increase in $\mathrm{O}_{3}$ concentration. Based on the analysis, we have also prioritized the pollutants according to their significance of variability among the Indian cities. It is observed that among the Tier-I cities, $\mathrm{NO}_{x}$ has shown the highest variability in maximum number of cities, followed by $\mathrm{PM}_{2.5}, \mathrm{NO}_{2}$ and $\mathrm{NH}_{3}$. Among the Tier-II cities, $\mathrm{CO}$ and $\mathrm{PM}$ (both $\mathrm{PM}_{2.5}$ and $\mathrm{PM}_{10}$ ) have shown significant variability in maximum number of cities, followed by $\mathrm{NO}_{x}$ and $\mathrm{O}_{3}$ concentrations. As mentioned above, the variations in $\mathrm{CO}$ and PM can be thought to be effected by reduced industrial emissions, while the variation in $\mathrm{O}_{3}$ has shown increasing trend in many cities owing to the favourable situations for secondary photochemical emissions in the lower atmosphere.

\section{Conclusions and recommendations}

The present study addresses the status of air quality in major Indian cities during various lockdown and unlocking phases during the COVID-19 pandemic spread compared to the pre-lockdown measures. The significance of considering long-term averaged values as references for evaluating the short-term impacts of lockdown series was evaluated using statistical tests. The observed variability in air quality in terms of AQI and its core elements were evaluated among the Tier-I and Tier-II cities as well as during regular phases of lockdown events. Furthermore, the study highlights the 
possibility of correlating the AQI with the initial trend of COVID-19 issues including the vaccination cases. The major conclusions drawn from the study are as follows:

1. The imposition of lockdown has caused invariably declining trend of concentrations for major air pollutants during various phases in 2020 compared to 2019. The highest reduction in concentration was observed during the middle stages of lockdown followed by a reversed trend during the unlocking phases. The results indicate that the current nature of trend cannot be generalized without referring to the specific attributes of the location. Statistical analysis infers that long-term averaging technique for representing the impacts of short-term pre-lockdown conditions can impose a healing effect to the observed anomalies despite the necessity to identify their extent.

2. The statistical significance analysis showed evidence for the reversing trends in air pollution for the partial unlocking phases, indicating that the earlier reductions in air pollution during the imposed lockdown series were only a phenomenal consequence. The variations in significant levels ( $p$ values) thus represent the influence of local administrative decisions to provide sufficient enforcement infrastructure during the complete lockdown period (March-May 2020). Remarkably, an oscillating trend of active COVID19 cases was visible in those cities.

3. The results suggest the existence of a strong relationship between the percentage variation in AQI (for 2019-2020) and the observed range of EF scores. However, the marginal reductions in EF during the study period alone cannot dictate any improvement in air quality as the concentrations of major air pollutants in many of the cities may be well beyond the national ambient air quality standards (NAAQS) being measured with respect to the worse scenario.

4. The trend analysis serves to be a preferable criterion to choose the preferred sources of variations despite the fact that there is incoherent variability in the pollutant distributions among the cities for various phases of the study. The results highlighted that consideration of long-term average as the reference for measuring the impacts of short-term LDS can give significant insights to the cause of pollution incidents and the effectiveness of their control strategies.

5. The correlation analysis revealed that air quality expressed in terms of AQI can act as an important precursor to estimate the critical phase of COVID-
19 spread and the effectiveness of various control measures taken during each phase. However, the study failed to identify any significant correlation between AQI and COVID-19 database for Tier-I cities except for the vaccination cases and recovery cases due to the variability introduced by a sequence of mutually exclusive events such as administration of massive vaccination drives and permission to hold local gatherings. The latest trends in vaccination drive amidst the onset of second wave of the pandemic have shown negative correlation with AQI for Delhi, Mumbai and Kolkata having large number of positive confirmed cases.

6. The 3 months of lockdown (during March-May 2020) and the following partial unlocking events were able to limit the active ratio and recovery ratio by enforcing strict precautions such as social distancing and wearing masks. Similarly, the first 3 months of onset of vaccination drive (JanuaryApril 2021) has resulted in reduced case fatality ratio despite the advancement in number of daily positive confirmed cases in major Indian cities. The correlation analysis suggests that the case fatality ratio may be modified by including the prominent diseases associated with air pollution to realize the actual impact of coronavirus on public health surveillance system, thereby incorporating a much wider aspect of air quality in COVID-19 impact studies.

7. As the COVID-19 impacts demarcate highly dynamic oscillatory trends, the linear correlation analysis proves insufficient to capture the original nature of observed deviations. A multi-criteria non-linear correlation model could realise the hidden interactions of coronavirus in the social atmosphere and its associated health risks.

8. Based on the results, a ranking is proposed for the Indian cities according to their responsiveness to various institutionalized restrictions in terms of air quality parameters. Among the Tier-I cities, Kolkata stands first, followed by Mumbai, Bengaluru and Chennai, signifying their resilience in reflecting the sudden changes in primary air pollutants during the LDS. The top three-ranked cities among the Tier-II category consist of Patna, Chandigarh and Visakhapatnam, followed by Thiruvananthapuram, Ahmedabad and Bhopal, indicating the influence of reduced industrial activities along with restricted public movement. However, caution must be exercised while interpreting the causes for the observed variations in view of the prevailing climatic, topographical, social and industrial conditions of the cities. 


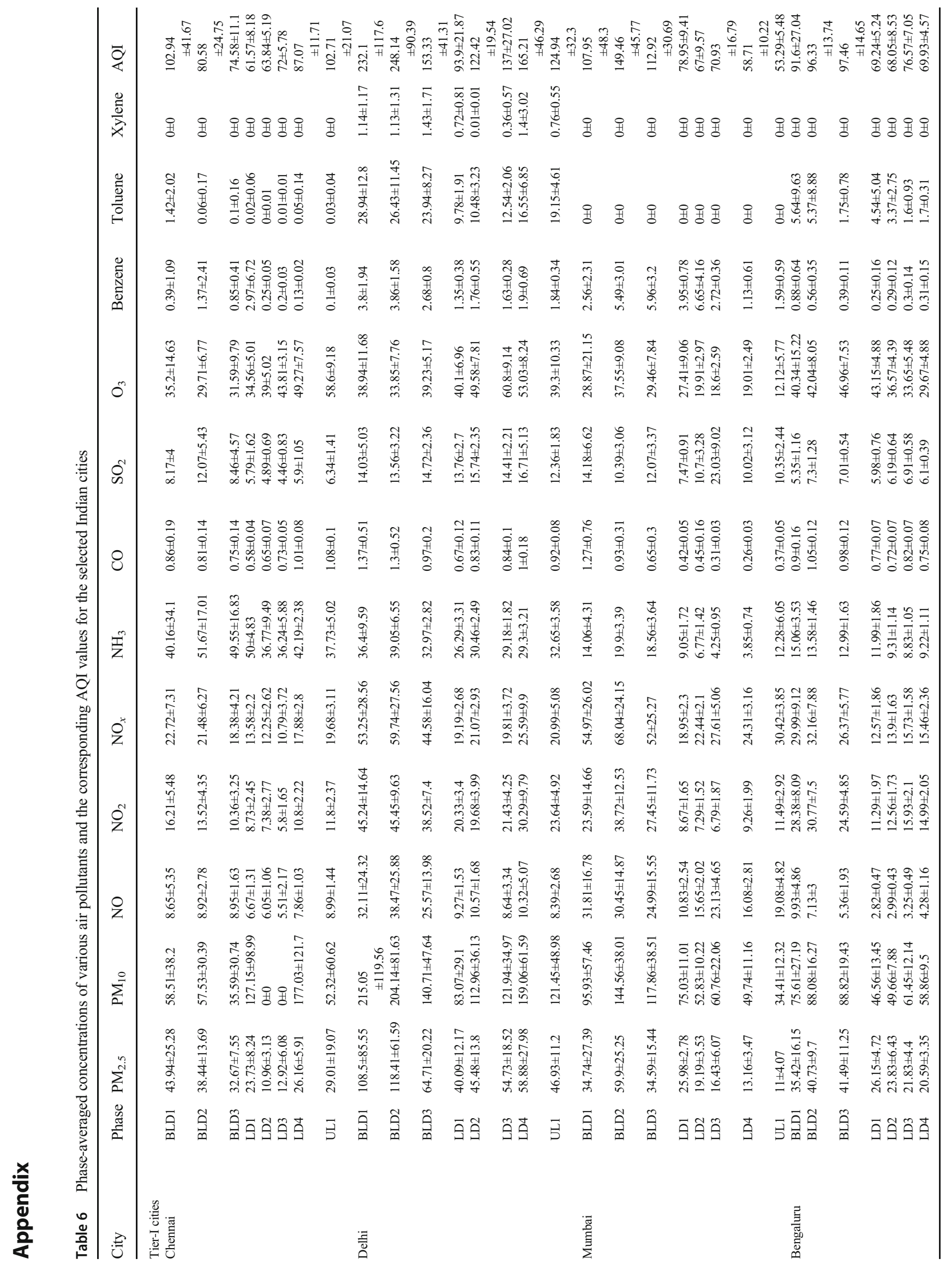




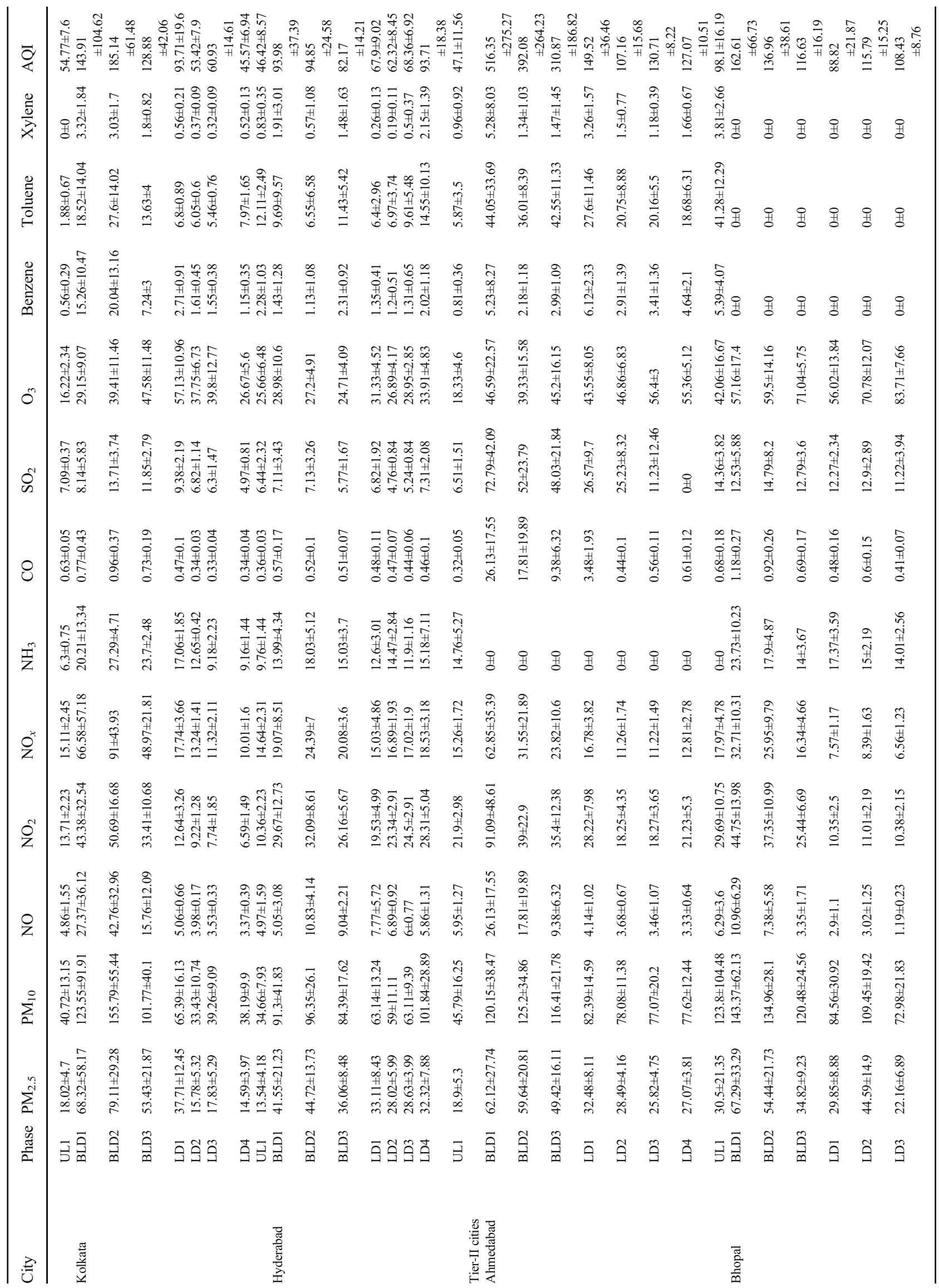




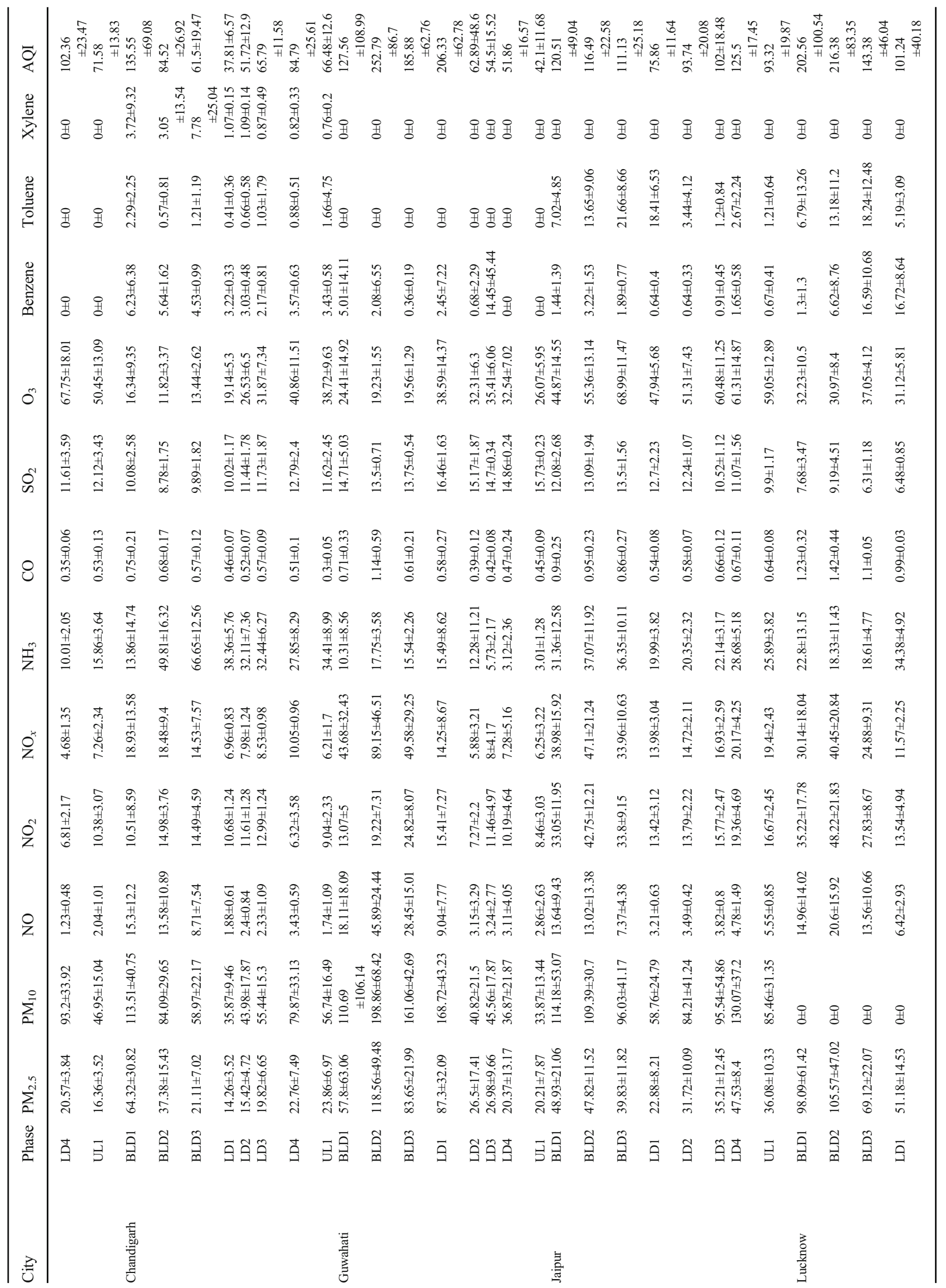




\begin{tabular}{|c|c|c|c|c|c|c|c|c|c|c|c|c|c|c|c|c|c|c|c|c|}
\hline & 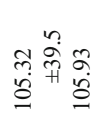 & & $\begin{array}{l}f \\
0 \\
0 \\
0\end{array}$ & & 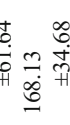 & 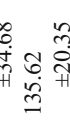 & & & & & & 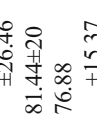 & 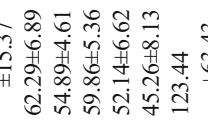 & & & & & & & $\underset{\infty}{\infty} \frac{\tilde{\alpha}}{+\infty}$ \\
\hline$\frac{\pi}{2}$ & 융 융 & 용 & $P_{0}=$ & 鬲 & $\stackrel{\vec{H}}{\stackrel{\vec{H}}{\rightleftarrows}}$ & $\begin{array}{l}\hat{a} \\
\text { în } \\
\text { Oे } \\
0 \\
0\end{array}$ & $\begin{array}{l}n \\
\text { ñ } \\
\text { i⿱ } \\
\text { f. } \\
0\end{array}$ & $\begin{array}{l}\stackrel{0}{0} \\
\text { Ò } \\
\text { İ } \\
\text { in }\end{array}$ & $\begin{array}{l}\stackrel{n}{0} \\
\stackrel{1}{2} \\
\stackrel{2}{2}\end{array}$ & 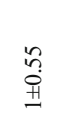 & 융 & 용융 & 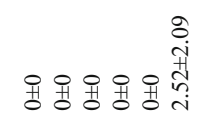 & 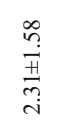 & 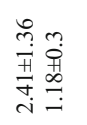 & 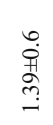 & & & & 苦 \\
\hline 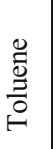 & 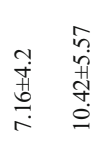 & 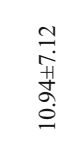 & 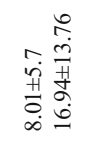 & $\begin{array}{l}\vec{m} \\
\stackrel{0}{0} \\
\vec{b}\end{array}$ & 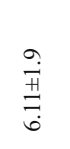 & 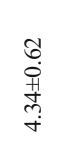 & 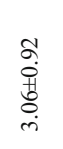 & 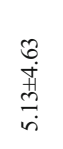 & $\begin{array}{l}\infty \\
\stackrel{\infty}{i} \\
\infty \\
\infty \\
\infty \\
\infty\end{array}$ & 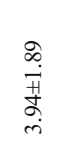 & 융 & 용융 & 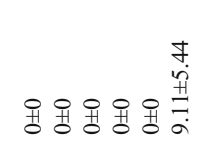 & 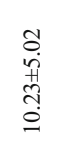 & 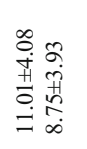 & & & & & $\underset{\infty}{\infty}$ \\
\hline 离 & 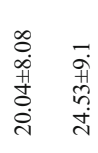 & $\begin{array}{l}\frac{m}{2} \\
\stackrel{1}{ \pm} \\
\frac{m}{2}\end{array}$ & 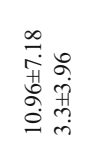 & 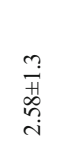 & $\begin{array}{l}= \\
\overrightarrow{\dot{H}} \\
\stackrel{+}{0} \\
\text { i }\end{array}$ & $\begin{array}{l}\hat{\hat{A}} \\
\dot{0} \\
\hat{\sigma} \\
\dot{0}\end{array}$ & $\begin{array}{l}\hat{n} \\
\hat{0} \\
0 \\
0 \\
0 \\
0\end{array}$ & $\underset{\substack{\hat{H} \\
\hat{i}}}{i}$ & 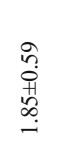 & 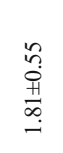 & 용 & 용 용 & 융용영용용 & 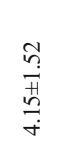 & 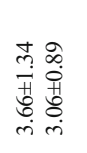 & $\begin{array}{c}\hat{0} \\
\text { in } \\
\hat{n} \\
i\end{array}$ & & a & & $\vec{\infty}$ \\
\hline రీ & 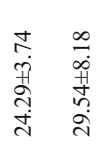 & 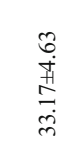 & 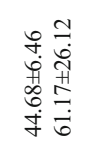 & 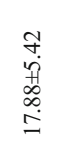 & 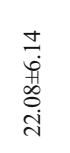 & 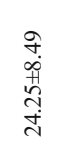 & 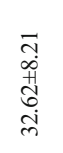 & 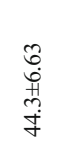 & 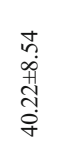 & 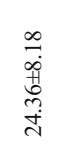 & 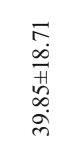 & 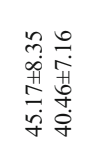 & 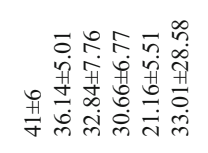 & $\begin{array}{l}a \\
\dot{a} \\
\frac{\vec{H}}{m} \\
\dot{m}\end{array}$ & 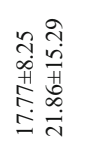 & $\begin{array}{l}\overline{\dot{0}} \\
\dot{\ddot{t}}\end{array}$ & $\infty$ & 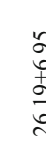 & & $\stackrel{\sim}{\infty}$ \\
\hline & 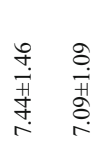 & 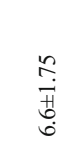 & 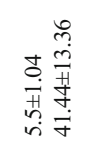 & $\underset{\substack{n \\
+\\
\alpha \\
\alpha}}{n}$ & 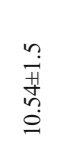 & 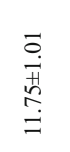 & $\begin{array}{l}\stackrel{\infty}{0} \\
\stackrel{+1}{0} \\
\stackrel{0}{0}\end{array}$ & $\begin{array}{l}\hat{0} \\
\tilde{T} \\
\stackrel{0}{0} \\
\sigma\end{array}$ & 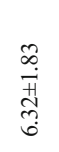 & 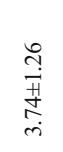 & 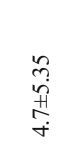 & 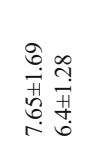 & 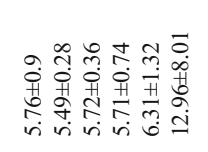 & $\begin{array}{l}\infty \\
\stackrel{\infty}{1} \\
\stackrel{1}{0} \\
\infty \\
\infty\end{array}$ & 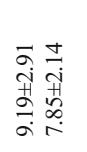 & m? & 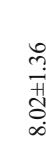 & $\begin{array}{c}7 \\
7 \\
z \\
\infty \\
\infty \\
\infty\end{array}$ & & $\begin{array}{l}\text { तु } \\
\text { d. } \\
\infty\end{array}$ \\
\hline o & 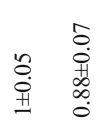 & 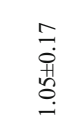 & 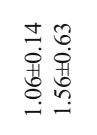 & 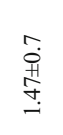 & 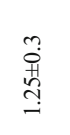 & 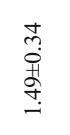 & 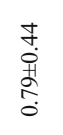 & 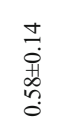 & $\begin{array}{l}\frac{1}{0} \\
0 \\
\frac{1}{n} \\
0\end{array}$ & $\begin{array}{l}\frac{n}{0} \\
\text { 荠 } \\
0\end{array}$ & $\begin{array}{l}\bar{n} \\
0 \\
0+1 \\
\infty \\
\infty \\
0 \\
0\end{array}$ & 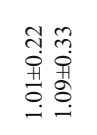 & 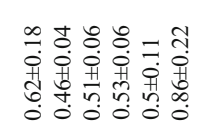 & $\begin{array}{l}\text { त̂ } \\
\text { 草 }\end{array}$ & 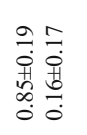 & P्म & $\frac{\text { 开 }}{0}$ & 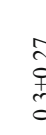 & & \\
\hline & 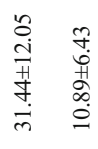 & 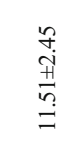 & 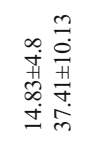 & 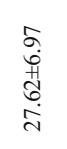 & 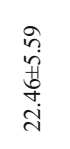 & 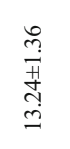 & 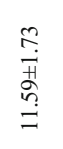 & 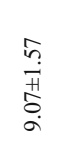 & 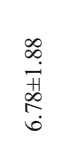 & 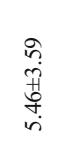 & $\begin{array}{l}\stackrel{8}{0} \\
\ddot{+} \\
0 \\
\dot{\sigma}\end{array}$ & 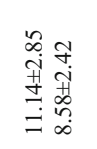 & 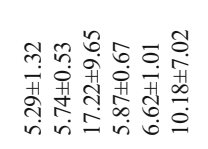 & 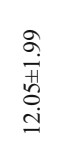 & 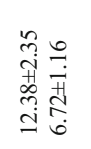 & $\begin{array}{l}\tilde{O} \\
\text { Oे } \\
\text { In }\end{array}$ & $\begin{array}{l}3 \\
\frac{3}{1} \\
\frac{1}{6}\end{array}$ & 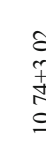 & & 菅 \\
\hline$\overbrace{}^{\prime}$ & 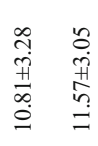 & $\begin{array}{l}\vec{F} \\
\stackrel{\oplus}{M} \\
\stackrel{M}{M}\end{array}$ & 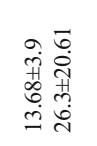 & 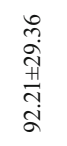 & 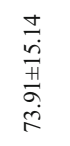 & $\begin{array}{l}\tilde{N} \\
\tilde{m} \\
\vec{\infty} \\
\infty \\
\dot{m} \\
\dot{m}\end{array}$ & $\begin{array}{c}\infty \\
\infty \\
\dot{+} \\
\frac{H}{n} \\
i n\end{array}$ & $\begin{array}{l}n \\
2 \\
\text { j } \\
+0 \\
\infty \\
0 \\
0\end{array}$ & 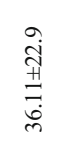 & 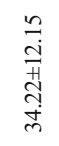 & 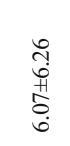 & 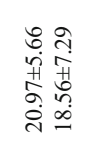 & 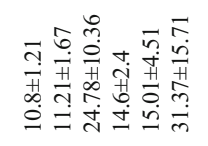 & $\begin{array}{l}\underset{i}{\Delta} \\
\underset{i}{+} \\
\underset{i}{+}\end{array}$ & 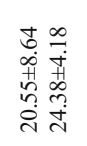 & $\begin{array}{l}\infty \\
0 \\
\infty \\
0 \\
0 \\
0 \\
0\end{array}$ & 6 & 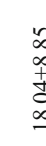 & & \\
\hline & 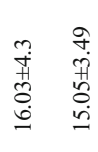 & 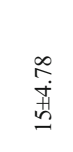 & 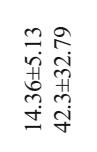 & 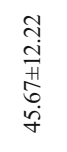 & 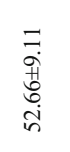 & 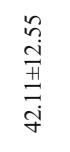 & 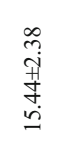 & 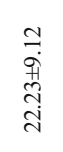 & $\begin{array}{l}n \\
\hat{n} \\
0 \\
0 \\
0 \\
0 \\
-1\end{array}$ & $\begin{array}{l}\stackrel{0}{2} \\
\stackrel{n}{+} \\
\stackrel{4}{4}\end{array}$ & 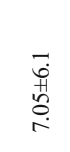 & 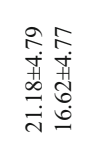 & 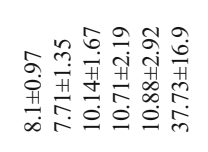 & $\begin{array}{l}\dot{q} \\
\dot{m} \\
\vec{H} \\
\alpha \\
\dot{m}\end{array}$ & 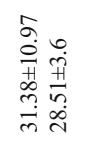 & 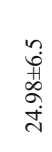 & 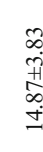 & 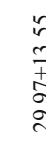 & & \\
\hline & 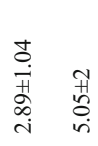 & 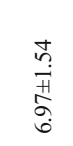 & 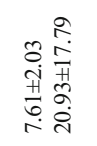 & 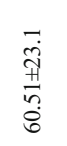 & $\begin{array}{l}n \\
i n \\
\infty \\
\frac{1}{H} \\
n \\
i n \\
i n\end{array}$ & 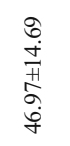 & 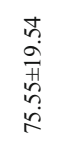 & 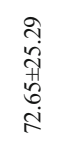 & 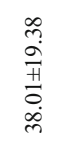 & 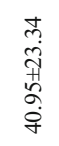 & 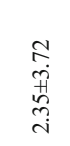 & 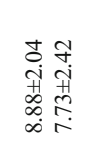 & 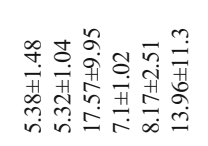 & 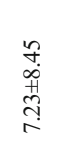 & 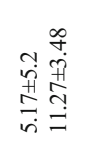 & 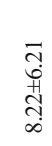 & 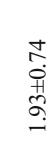 & 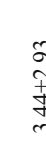 & & \\
\hline$\sum^{5}$ & 융 용 & 융 & 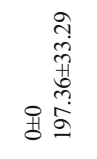 & 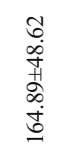 & 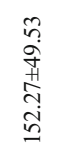 & 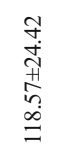 & $\begin{array}{l}\mathscr{\infty} \\
\stackrel{\infty}{\pi} \\
\text { तै } \\
\stackrel{i}{+}\end{array}$ & 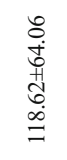 & 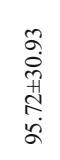 & $\begin{array}{l}\text { त्र } \\
\text { ग̃ } \\
0 \\
0 \\
\text { d }\end{array}$ & $\begin{array}{l}2 \\
\text { in } \\
\text { In } \\
\text { ri } \\
\text { n. }\end{array}$ & 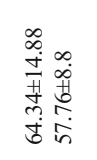 & 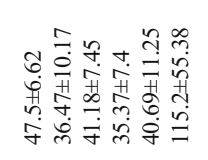 & 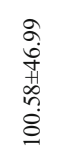 & 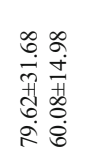 & 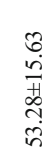 & 7 & 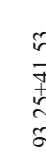 & & \\
\hline & 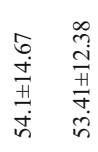 & $\begin{array}{l}\infty \\
\infty \\
0 \\
\mathbb{1} \\
0 \\
0 \\
3\end{array}$ & 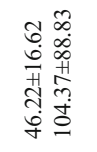 & 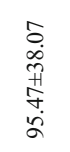 & 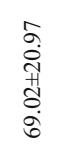 & $\begin{array}{l}\infty \\
\infty \\
\stackrel{\vec{H}}{+} \\
\dot{+} \\
\dot{\infty} \\
\dot{n}\end{array}$ & 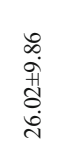 & 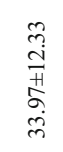 & 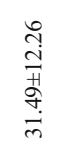 & 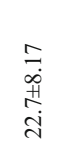 & 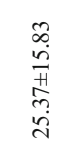 & 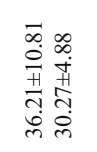 & 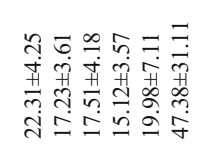 & 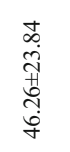 & 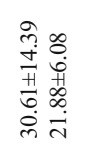 & iी & $\dot{f}$ & 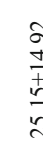 & & \\
\hline $\begin{array}{l}0 \\
\frac{\mathscr{Z}}{\pi} \\
\frac{\pi}{2}\end{array}$ & $\tilde{a}$ & 苛 & $\vec{亏} \overline{\hat{P}_{m}}$ & กิ๊ & 气̣̂ & $\overrightarrow{9}$ & قิ & $\tilde{a}$ & 莟 & $\overrightarrow{5}$ & $\overrightarrow{\hat{\oplus}^{\prime}}$ & 今్ & 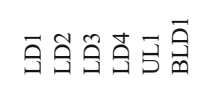 & 气ิ & 解 & & & 7 & & \\
\hline & & & 馬 & & & & & & & & 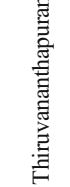 & & & & & & & & & \\
\hline
\end{tabular}


Table 7 Phase-averaged COVID-19 database with the corresponding AQI values for the selected Indian cities

\begin{tabular}{|c|c|c|c|c|c|c|c|c|c|c|c|}
\hline \multirow[t]{2}{*}{ City } & \multirow[t]{2}{*}{ Phase } & \multirow{2}{*}{$\begin{array}{l}\text { No. of } \\
\text { days }\end{array}$} & \multirow{2}{*}{$\begin{array}{l}\text { Average } \\
\text { AQI }\end{array}$} & \multicolumn{5}{|c|}{ COVID-19 database } & \multicolumn{3}{|c|}{ COVID-19 impacts } \\
\hline & & & & $\begin{array}{l}\text { Positive } \\
\text { confirmed } \\
\text { cases }\end{array}$ & $\begin{array}{l}\text { Deceased } \\
\text { cases }\end{array}$ & $\begin{array}{l}\text { Active } \\
\text { cases }\end{array}$ & $\begin{array}{l}\text { Recovered } \\
\text { cases }\end{array}$ & $\begin{array}{l}\text { Vaccination } \\
\text { cases }\end{array}$ & $\begin{array}{l}\text { Activity } \\
\text { ratio }\end{array}$ & $\begin{array}{l}\text { Recovery } \\
\text { ratio }\end{array}$ & $\begin{array}{l}\text { Case } \\
\text { fatality } \\
\text { ratio }\end{array}$ \\
\hline \multicolumn{12}{|l|}{ Tier-I cities } \\
\hline \multirow[t]{14}{*}{ Chennai } & LD1 & 21 & 61.6 & 0 & 0 & 0 & 0 & & & & \\
\hline & LD2 & 19 & 63.8 & 1463 & 17 & 1196 & 250 & & 81.75 & 17.09 & 1.16 \\
\hline & LD3 & 14 & 72.0 & 5298 & 37 & 4035 & 1226 & & 76.16 & 23.14 & 0.70 \\
\hline & LD4 & 14 & 87.1 & 8038 & 78 & 1545 & 6415 & & 19.22 & 79.81 & 0.97 \\
\hline & UL1 & 30 & 102.7 & 43528 & 753 & 15838 & 26937 & & 36.39 & 61.88 & 1.73 \\
\hline & UL2 & 31 & 75.0 & 41467 & 1225 & -9846 & 50088 & & -23.74 & 120.79 & 2.95 \\
\hline & UL3 & 31 & 68.0 & 35803 & 634 & 459 & 34710 & & 1.28 & 96.95 & 1.77 \\
\hline & UL4 & 30 & 51.8 & 31779 & 463 & -1904 & 33220 & & -5.99 & 104.53 & 1.46 \\
\hline & UL5 & 31 & 80.8 & 32540 & 441 & -4129 & 36228 & & -12.69 & 111.33 & 1.36 \\
\hline & UL6 & 30 & 82.9 & 15444 & 199 & -3442 & 18301 & & -22.29 & 118.50 & 1.29 \\
\hline & UL7 & 46 & 80.8 & 13551 & 212 & -1803 & 15341 & & -13.31 & 113.21 & 1.56 \\
\hline & UL8 & 31 & 86.3 & 4571 & 63 & -378 & 5073 & 28807 & -8.27 & 110.98 & 1.38 \\
\hline & UL9 & 28 & 61.5 & 5649 & 54 & 455 & 5140 & 225197 & 8.05 & 90.99 & 0.96 \\
\hline & UL10 & 31 & 71.5 & 35603 & 174 & 19368 & 16061 & 774558 & 54.40 & 45.11 & 0.49 \\
\hline \multirow[t]{14}{*}{ Delhi } & LD1 & 21 & 93.9 & 1531 & 30 & 1470 & 31 & & 96.02 & 2.02 & 1.96 \\
\hline & LD2 & 19 & 122.4 & 2988 & 34 & 1623 & 1331 & & 54.32 & 44.54 & 1.14 \\
\hline & LD3 & 14 & 137.0 & 5206 & 84 & 2282 & 2840 & & 43.83 & 54.55 & 1.61 \\
\hline & LD4 & 14 & 165.2 & 10089 & 325 & 5488 & 4276 & & 54.40 & 42.38 & 3.22 \\
\hline & UL1 & 30 & 124.9 & 67516 & 2269 & 15377 & 49870 & & 22.78 & 73.86 & 3.36 \\
\hline & UL2 & 31 & 68.6 & 48238 & 1221 & -15565 & 62582 & & -32.27 & 129.74 & 2.53 \\
\hline & UL3 & 31 & 98.0 & 39150 & 481 & 3921 & 34748 & & 10.02 & 88.76 & 1.23 \\
\hline & UL4 & 30 & 135.4 & 104967 & 917 & 12282 & 91768 & & 11.70 & 87.43 & 0.87 \\
\hline & UL5 & 31 & 323.7 & 106991 & 1150 & 5811 & 100030 & & 5.43 & 93.49 & 1.07 \\
\hline & UL6 & 30 & 369.0 & 183668 & 2663 & 166 & 180839 & & 0.09 & 98.46 & 1.45 \\
\hline & UL7 & 46 & 450.0 & 61809 & 1564 & -30194 & 90042 & & -48.85 & 145.68 & 2.53 \\
\hline & UL8 & 31 & 322.2 & 4904 & 155 & -1655 & 6801 & 206172 & -33.75 & 138.68 & 3.16 \\
\hline & UL9 & 28 & 243.8 & 6977 & 51 & 1285 & 5641 & 740756 & 18.42 & 80.85 & 0.73 \\
\hline & UL10 & 31 & 215.5 & 140073 & 708 & 51988 & 87377 & 1508037 & 37.11 & 62.38 & 0.51 \\
\hline \multirow[t]{14}{*}{ Mumbai } & LD1 & 21 & 79.0 & 0 & 0 & 0 & 0 & & & & \\
\hline & LD2 & 19 & 67.0 & 8800 & 326 & 213 & 130 & & 2.42 & 1.48 & 3.70 \\
\hline & LD3 & 14 & 70.9 & 11350 & 408 & 424 & 3368 & & 3.74 & 29.67 & 3.59 \\
\hline & LD4 & 14 & 58.7 & 19536 & 545 & -187 & 13293 & & -0.96 & 68.04 & 2.79 \\
\hline & UL1 & 30 & 53.3 & 37972 & 3277 & 2273 & 27379 & & 5.99 & 72.10 & 8.63 \\
\hline & UL2 & 31 & 47.0 & 36626 & 1797 & 2441 & 42904 & & 6.66 & 117.14 & 4.91 \\
\hline & UL3 & 31 & 37.7 & 31521 & 1305 & -342 & 30194 & & -1.08 & 95.79 & 4.14 \\
\hline & UL4 & 30 & 58.7 & 59463 & 1271 & 4899 & 52000 & & 8.24 & 87.45 & 2.14 \\
\hline & UL5 & 31 & 82.7 & 52229 & 1364 & -8609 & 58422 & & -16.48 & 111.86 & 2.61 \\
\hline & UL6 & 30 & 123.4 & 25970 & 591 & -49 & 28613 & & -0.19 & 110.18 & 2.28 \\
\hline & UL7 & 46 & 244.6 & 18188 & 345 & -383 & 26130 & & -2.11 & 143.67 & 1.90 \\
\hline & UL8 & 31 & 191.0 & 12914 & 193 & -48 & 15737 & 119576 & -0.37 & 121.86 & 1.49 \\
\hline & UL9 & 28 & 144.7 & 29393 & 117 & 7267 & 21757 & 314584 & 24.72 & 74.02 & 0.40 \\
\hline & UL10 & 31 & 130.9 & 209442 & 658 & 76854 & 135366 & 1434179 & 36.69 & 64.63 & 0.31 \\
\hline \multirow[t]{14}{*}{ Bengaluru } & LD1 & 21 & 69.2 & 0 & 0 & 0 & 0 & & & & \\
\hline & LD2 & 19 & 68.1 & 149 & 6 & 70 & 72 & & 46.98 & 48.32 & 4.03 \\
\hline & LD3 & 14 & 76.6 & 67 & 1 & 16 & 50 & & 23.88 & 74.63 & 1.49 \\
\hline & LD4 & 14 & 69.9 & 143 & 3 & 31 & 109 & & 21.68 & 76.22 & 2.10 \\
\hline & UL1 & 30 & 54.8 & 4196 & 85 & 3798 & 313 & & 90.51 & 7.46 & 2.03 \\
\hline & UL2 & 31 & 35.0 & 50989 & 934 & 33703 & 16352 & & 66.10 & 32.07 & 1.83 \\
\hline & UL3 & 31 & 24.1 & 73581 & 936 & -502 & 73147 & & -0.68 & 99.41 & 1.27 \\
\hline & UL4 & 30 & 44.4 & 103538 & 971 & 10029 & 92538 & & 9.69 & 89.38 & 0.94 \\
\hline & UL5 & 31 & 74.8 & 103806 & 928 & -16547 & 115564 & & -15.94 & 111.33 & 0.89 \\
\hline & UL6 & 30 & 86.4 & 33265 & 273 & -13350 & 50203 & & -40.13 & 150.92 & 0.82 \\
\hline & UL7 & 46 & 101.6 & 24479 & 220 & -11538 & 35797 & & -47.13 & 146.24 & 0.90 \\
\hline & UL8 & 31 & 89.3 & 7999 & 73 & -1812 & 9688 & 108784 & -22.65 & 121.12 & 0.91 \\
\hline & UL9 & 28 & 73.3 & 9777 & 94 & 2556 & 7177 & 251552 & 26.14 & 73.41 & 0.96 \\
\hline & UL10 & 31 & 92.5 & 100532 & 439 & 65373 & 34720 & 1009878 & 65.03 & 34.54 & 0.44 \\
\hline \multirow[t]{4}{*}{ Kolkata } & LD1 & 21 & 93.7 & 0 & 0 & 0 & 0 & & & & \\
\hline & LD2 & 19 & 53.4 & 635 & 0 & 453 & 95 & & 71.34 & 14.96 & 0.00 \\
\hline & LD3 & 14 & 60.9 & 736 & 216 & 220 & 383 & & 29.89 & 52.04 & 29.35 \\
\hline & LD4 & 14 & 45.6 & 754 & 626 & 341 & 424 & & 45.23 & 56.23 & 83.02 \\
\hline
\end{tabular}


Table 7 (continued)

\begin{tabular}{|c|c|c|c|c|c|c|c|c|c|c|c|}
\hline \multirow[t]{2}{*}{ City } & \multirow[t]{2}{*}{ Phase } & \multirow{2}{*}{$\begin{array}{l}\text { No. of } \\
\text { days }\end{array}$} & \multirow{2}{*}{$\begin{array}{l}\text { Average } \\
\text { AQI }\end{array}$} & \multicolumn{5}{|c|}{ COVID-19 database } & \multicolumn{3}{|c|}{ COVID-19 impacts } \\
\hline & & & & $\begin{array}{l}\text { Positive } \\
\text { confirmed } \\
\text { cases }\end{array}$ & $\begin{array}{l}\text { Deceased } \\
\text { cases }\end{array}$ & $\begin{array}{l}\text { Active } \\
\text { cases }\end{array}$ & $\begin{array}{l}\text { Recovered } \\
\text { cases }\end{array}$ & $\begin{array}{l}\text { Vaccination } \\
\text { cases }\end{array}$ & $\begin{array}{l}\text { Activity } \\
\text { ratio }\end{array}$ & $\begin{array}{l}\text { Recovery } \\
\text { ratio }\end{array}$ & $\begin{array}{l}\text { Case } \\
\text { fatality } \\
\text { ratio }\end{array}$ \\
\hline & UL1 & 30 & 46.4 & 3859 & 599 & 838 & 2851 & & 21.72 & 73.88 & 15.52 \\
\hline & UL2 & 31 & 42.0 & 15655 & 156 & 4521 & 10753 & & 28.88 & 68.69 & 1.00 \\
\hline & UL3 & 31 & 41.0 & 18518 & 118 & -1664 & 19652 & & -8.99 & 106.12 & 0.64 \\
\hline & UL4 & 30 & 40.0 & 16255 & 97 & 564 & 15271 & & 3.47 & 93.95 & 0.60 \\
\hline & UL5 & 31 & 40.6 & 24876 & 90 & 1666 & 22714 & & 6.70 & 91.31 & 0.36 \\
\hline & UL6 & 30 & 159.4 & 25445 & 158 & -502 & 25545 & & -1.97 & 100.39 & 0.62 \\
\hline & UL7 & 46 & 272.5 & 19688 & 980 & -5017 & 24273 & & -25.48 & 123.29 & 4.98 \\
\hline & UL8 & 31 & 258.7 & 2210 & 50 & -340 & 2451 & 84837 & -15.38 & 110.90 & 2.26 \\
\hline & UL9 & 28 & 174.7 & 1959 & 19 & 202 & 1787 & 205654 & 10.31 & 91.22 & 0.97 \\
\hline & UL10 & 31 & 141.4 & 16368 & 73 & 9053 & 7242 & 592260 & 55.31 & 44.24 & 0.45 \\
\hline \multirow[t]{14}{*}{ Hyderabad } & LD1 & 21 & 67.9 & 605 & 0 & 477 & 110 & & 78.84 & 18.18 & 0.00 \\
\hline & LD2 & 19 & 62.3 & 438 & 29 & -8 & 435 & & -1.83 & 99.32 & 6.62 \\
\hline & LD3 & 14 & 68.4 & 469 & 5 & 17 & 447 & & 3.62 & 95.31 & 1.07 \\
\hline & LD4 & 14 & 93.7 & 1147 & 48 & 663 & 436 & & 57.80 & 38.01 & 4.18 \\
\hline & UL1 & 30 & 47.1 & 13641 & 178 & 7597 & 5866 & & 55.69 & 43.00 & 1.30 \\
\hline & UL2 & 31 & 54.0 & 46364 & 259 & 8011 & 38094 & & 17.28 & 82.16 & 0.56 \\
\hline & UL3 & 31 & 45.0 & 62260 & 308 & 14503 & 47449 & & 23.29 & 76.21 & 0.49 \\
\hline & UL4 & 30 & 37.7 & 66423 & 300 & -1973 & 68096 & & -2.97 & 102.52 & 0.45 \\
\hline & UL5 & 31 & 98.4 & 45801 & 209 & -10917 & 57954 & & -23.84 & 126.53 & 0.46 \\
\hline & UL6 & 30 & 145.3 & 31999 & 122 & -8387 & 39449 & & -26.21 & 123.28 & 0.38 \\
\hline & UL7 & 46 & 187.2 & 21932 & 116 & -5580 & 26766 & & -25.44 & 122.04 & 0.53 \\
\hline & UL8 & 31 & 122.4 & 5555 & 44 & -2766 & 8277 & 293442 & -49.79 & 149.00 & 0.79 \\
\hline & UL9 & 28 & 112.8 & 4645 & 36 & 307 & 4302 & 401369 & 6.61 & 92.62 & 0.78 \\
\hline & UL10 & 31 & 122.5 & 36727 & 134 & 25878 & 10715 & 1927705 & 70.46 & 29.17 & 0.36 \\
\hline \multicolumn{12}{|l|}{ Tier-II cities } \\
\hline \multirow[t]{14}{*}{ Ahmedabad } & LD1 & 21 & 149.5 & 0 & 0 & 0 & 0 & & & & \\
\hline & LD2 & 19 & 107.2 & 3817 & 0 & 3076 & 533 & & 80.59 & 13.96 & 0.00 \\
\hline & LD3 & 14 & 130.7 & 4603 & 216 & 2160 & 2127 & & 46.93 & 46.21 & 4.69 \\
\hline & LD4 & 14 & 127.1 & 3760 & 626 & -816 & 4258 & & -21.70 & 113.24 & 16.65 \\
\hline & UL1 & 30 & 98.1 & 8733 & 599 & -916 & 9050 & & -10.49 & 103.63 & 6.86 \\
\hline & UL2 & 31 & 84.0 & 5604 & 156 & -52 & 5500 & & -0.93 & 98.14 & 2.78 \\
\hline & UL3 & 31 & 82.0 & 5002 & 118 & -19 & 4987 & & -0.38 & 99.70 & 2.36 \\
\hline & UL4 & 30 & 81.0 & 5329 & 97 & 755 & 4393 & & 14.17 & 82.44 & 1.82 \\
\hline & UL5 & 31 & 135.0 & 5666 & 90 & -910 & 6486 & & -16.06 & 114.47 & 1.59 \\
\hline & UL6 & 30 & 151.0 & 7563 & 158 & -100 & 7505 & & -1.32 & 99.23 & 2.09 \\
\hline & UL7 & 46 & 193.0 & 9562 & 216 & -626 & 9972 & & -6.55 & 104.29 & 2.26 \\
\hline & UL8 & 31 & 167.9 & 2197 & 29 & -2008 & 4176 & 109936 & -91.40 & 190.08 & 1.32 \\
\hline & UL9 & 28 & 160.3 & 3009 & 18 & 365 & 2626 & 188026 & 12.13 & 87.27 & 0.60 \\
\hline & UL10 & 31 & 170.2 & 27467 & 219 & 12243 & 15005 & 923822 & 44.57 & 54.63 & 0.80 \\
\hline \multirow[t]{14}{*}{ Bhopal } & LD1 & 21 & 88.8 & 0 & 0 & 0 & 0 & & & & \\
\hline & LD2 & 19 & 115.8 & 532 & 15 & 280 & 237 & & 52.63 & 44.55 & 2.82 \\
\hline & LD3 & 14 & 108.4 & 460 & 23 & 110 & 327 & & 23.91 & 71.09 & 5.00 \\
\hline & LD4 & 14 & 102.4 & 475 & 19 & 57 & 399 & & 12.00 & 84.00 & 4.00 \\
\hline & UL1 & 30 & 71.6 & 1322 & 40 & 51 & 1231 & & 3.86 & 93.12 & 3.03 \\
\hline & UL2 & 31 & 57.3 & 3524 & 79 & 1676 & 1769 & & 47.56 & 50.20 & 2.24 \\
\hline & UL3 & 31 & 38.9 & 4183 & 109 & -604 & 4678 & & -14.44 & 111.83 & 2.61 \\
\hline & UL4 & 30 & 122.0 & 6912 & 107 & 533 & 6272 & & 7.71 & 90.74 & 1.55 \\
\hline & UL5 & 31 & 163.0 & 7218 & 88 & -579 & 7709 & & -8.02 & 106.80 & 1.22 \\
\hline & UL6 & 30 & 204.0 & 7348 & 38 & 1370 & 5940 & & 18.64 & 80.84 & 0.52 \\
\hline & UL7 & 46 & 282.0 & 9419 & 77 & -888 & 10230 & & -9.43 & 108.61 & 0.82 \\
\hline & UL8 & 31 & 148.7 & 1903 & 22 & -1450 & 3331 & 43954 & -76.20 & 175.04 & 1.16 \\
\hline & UL9 & 28 & 130.5 & 2239 & 5 & 422 & 1812 & 71378 & 18.85 & 80.93 & 0.22 \\
\hline & UL10 & 31 & 156.3 & 18006 & 44 & 6336 & 11626 & 339929 & 35.19 & 64.57 & 0.24 \\
\hline \multirow[t]{8}{*}{ Chandigarh } & LD1 & 21 & 37.8 & 14 & 0 & 7 & 7 & & 50.00 & 50.00 & 0.00 \\
\hline & LD2 & 19 & 51.7 & 76 & 1 & 63 & 12 & & 82.89 & 15.79 & 1.32 \\
\hline & LD3 & 14 & 65.8 & 94 & 3 & 60 & 32 & & 63.83 & 34.04 & 3.19 \\
\hline & LD4 & 14 & 84.8 & 102 & 0 & -47 & 148 & & -46.08 & 145.10 & 0.00 \\
\hline & UL1 & 30 & 66.5 & 147 & 2 & -20 & 165 & & -13.61 & 112.24 & 1.36 \\
\hline & UL2 & 31 & 34.0 & 611 & 9 & 299 & 303 & & 48.94 & 49.59 & 1.47 \\
\hline & UL3 & 31 & 65.5 & 3295 & 41 & 1488 & 1764 & & 45.16 & 53.54 & 1.24 \\
\hline & UL4 & 30 & 97.0 & 7592 & 106 & 106 & 7382 & & 1.40 & 97.23 & 1.40 \\
\hline
\end{tabular}


Table 7 (continued)

\begin{tabular}{|c|c|c|c|c|c|c|c|c|c|c|c|}
\hline \multirow[t]{2}{*}{ City } & \multirow[t]{2}{*}{ Phase } & \multirow{2}{*}{$\begin{array}{l}\text { No. of } \\
\text { days }\end{array}$} & \multirow{2}{*}{$\begin{array}{l}\text { Average } \\
\text { AQI }\end{array}$} & \multicolumn{5}{|c|}{ COVID-19 database } & \multicolumn{3}{|c|}{ COVID-19 impacts } \\
\hline & & & & $\begin{array}{l}\text { Positive } \\
\text { confirmed } \\
\text { cases }\end{array}$ & $\begin{array}{l}\text { Deceased } \\
\text { cases }\end{array}$ & $\begin{array}{l}\text { Active } \\
\text { cases }\end{array}$ & $\begin{array}{l}\text { Recovered } \\
\text { cases }\end{array}$ & $\begin{array}{l}\text { Vaccination } \\
\text { cases }\end{array}$ & $\begin{array}{l}\text { Activity } \\
\text { ratio }\end{array}$ & $\begin{array}{l}\text { Recovery } \\
\text { ratio }\end{array}$ & $\begin{array}{l}\text { Case } \\
\text { fatality } \\
\text { ratio }\end{array}$ \\
\hline & UL5 & 31 & 121.4 & 2480 & 64 & -1322 & 3738 & & -53.31 & 150.73 & 2.58 \\
\hline & UL6 & 30 & 142.5 & 2991 & 51 & 421 & 2519 & & 14.08 & 84.22 & 1.71 \\
\hline & UL7 & 46 & 239.0 & 3055 & 53 & -796 & 3798 & & -26.06 & 124.32 & 1.73 \\
\hline & UL8 & 31 & 128.0 & 800 & 16 & -137 & 945 & 9356 & -17.13 & 118.13 & 2.00 \\
\hline & UL9 & 28 & 109.9 & 1980 & 12 & 1037 & 907 & 44422 & 52.37 & 45.81 & 0.61 \\
\hline & UL10 & 31 & 113.6 & 9153 & 49 & 2205 & 6899 & 80785 & 24.09 & 75.37 & 0.54 \\
\hline \multirow[t]{14}{*}{ Guwahati } & LD1 & 21 & 206.3 & 33 & 0 & 32 & 0 & & 96.97 & 0.00 & 0.00 \\
\hline & LD2 & 19 & 62.9 & 10 & 1 & -23 & 33 & & -230.00 & 330.00 & 10.00 \\
\hline & LD3 & 14 & 54.5 & 58 & 1 & 48 & 9 & & 82.76 & 15.52 & 1.72 \\
\hline & LD4 & 14 & 51.9 & 1239 & 2 & 1090 & 144 & & 87.97 & 11.62 & 0.16 \\
\hline & UL1 & 30 & 42.1 & 7068 & 8 & 1598 & 5462 & & 22.61 & 77.28 & 0.11 \\
\hline & UL2 & 31 & 37.0 & 31862 & 86 & 7066 & 24710 & & 22.18 & 77.55 & 0.27 \\
\hline & UL3 & 31 & 31.0 & 68771 & 208 & 13462 & 55101 & & 19.58 & 80.12 & 0.30 \\
\hline & UL4 & 30 & 54.0 & 71770 & 391 & 11223 & 60156 & & 15.64 & 83.82 & 0.54 \\
\hline & UL5 & 31 & 94.0 & 25540 & 233 & -25129 & 50436 & & -98.39 & 197.48 & 0.91 \\
\hline & UL6 & 30 & 126.0 & 6425 & 51 & -5968 & 12342 & & -92.89 & 192.09 & 0.79 \\
\hline & UL7 & 46 & 276.0 & 4001 & 85 & -1783 & 4352 & & -44.56 & 108.77 & 2.12 \\
\hline & UL8 & 31 & 255.7 & 527 & 23 & -1349 & 1870 & 132475 & -255.98 & 354.84 & 4.36 \\
\hline & UL9 & 28 & 199.2 & 513 & 10 & -2 & 491 & 412430 & -0.39 & 95.71 & 1.95 \\
\hline & UL10 & 31 & 210.6 & 4550 & 24 & 3348 & 1178 & 1010556 & 73.58 & 25.89 & 0.53 \\
\hline \multirow[t]{14}{*}{ Jaipur } & LD1 & 21 & 75.9 & 0 & 0 & 0 & 0 & & & & \\
\hline & LD2 & 19 & 93.7 & 993 & 40 & 553 & 400 & & 55.69 & 40.28 & 4.03 \\
\hline & LD3 & 14 & 102.0 & 583 & 26 & 41 & 516 & & 7.03 & 88.51 & 4.46 \\
\hline & LD4 & 14 & 125.5 & 415 & 25 & -309 & 699 & & -74.46 & 168.43 & 6.02 \\
\hline & UL1 & 30 & 93.3 & 1327 & 69 & 290 & 968 & & 21.85 & 72.95 & 5.20 \\
\hline & UL2 & 31 & 87.0 & 2100 & 28 & 652 & 1420 & & 31.05 & 67.62 & 1.33 \\
\hline & UL3 & 31 & 93.0 & 5373 & 87 & 2566 & 2649 & & 47.76 & 49.30 & 1.62 \\
\hline & UL4 & 30 & 100.0 & 10697 & 46 & 3976 & 6746 & & 37.17 & 63.06 & 0.43 \\
\hline & UL5 & 31 & 142.3 & 11880 & 52 & -3674 & 15502 & & -30.93 & 130.49 & 0.44 \\
\hline & UL6 & 30 & 144.3 & 14403 & 62 & 5230 & 9111 & & 36.31 & 63.26 & 0.43 \\
\hline & UL7 & 46 & 140.5 & 10618 & 74 & -8152 & 18668 & & -76.78 & 175.81 & 0.70 \\
\hline & UL8 & 31 & 141.6 & 831 & 8 & -893 & 1744 & 64211 & -107.46 & 209.87 & 0.96 \\
\hline & UL9 & 28 & 117.8 & 827 & 2 & 230 & 595 & 179315 & 27.81 & 71.95 & 0.24 \\
\hline & UL10 & 31 & 136.1 & 11044 & 28 & 8694 & 2322 & 654105 & 78.72 & 21.02 & 0.25 \\
\hline \multirow[t]{14}{*}{ Lucknow } & LD1 & 21 & 101.2 & 0 & 0 & 0 & 0 & & & & \\
\hline & LD2 & 19 & 105.3 & 226 & 1 & 156 & 69 & & 69.03 & 30.53 & 0.44 \\
\hline & LD3 & 14 & 105.9 & 69 & 0 & -93 & 162 & & -134.78 & 234.78 & 0.00 \\
\hline & LD4 & 14 & 142.6 & 91 & 2 & 20 & 69 & & 21.98 & 75.82 & 2.20 \\
\hline & UL1 & 30 & 95.8 & 752 & 16 & 347 & 388 & & 46.14 & 51.60 & 2.13 \\
\hline & UL2 & 31 & 87.0 & 7040 & 76 & 3851 & 3114 & & 54.70 & 44.23 & 1.08 \\
\hline & UL3 & 31 & 112.0 & 19250 & 266 & 2893 & 16091 & & 15.03 & 83.59 & 1.38 \\
\hline & UL4 & 30 & 160.5 & 25341 & 342 & -387 & 25386 & & -1.53 & 100.18 & 1.35 \\
\hline & UL5 & 31 & 248.8 & 10493 & 175 & -3637 & 13955 & & -34.66 & 132.99 & 1.67 \\
\hline & UL6 & 30 & 351.9 & 8507 & 117 & 498 & 7892 & & 5.85 & 92.77 & 1.38 \\
\hline & UL7 & 46 & 381.9 & 8707 & 156 & -1515 & 10066 & & -17.40 & 115.61 & 1.79 \\
\hline & UL8 & 31 & 291.2 & 1221 & 36 & -1755 & 2940 & 0 & -143.73 & 240.79 & 2.95 \\
\hline & UL9 & 28 & 207.5 & 470 & 2 & -116 & 584 & 134971 & -24.68 & 124.26 & 0.43 \\
\hline & UL10 & 31 & 198.1 & 45128 & 221 & 35603 & 9304 & 321292 & 78.89 & 20.62 & 0.49 \\
\hline \multirow[t]{13}{*}{ Patna } & LD1 & 21 & 135.6 & 0 & 0 & 0 & 0 & & & & \\
\hline & LD2 & 19 & 125.2 & 44 & 0 & 31 & 13 & & 70.45 & 29.55 & 0.00 \\
\hline & LD3 & 14 & 162.2 & 120 & 2 & 89 & 29 & & 74.17 & 24.17 & 1.67 \\
\hline & LD4 & 14 & 114.8 & 87 & 0 & 27 & 60 & & 31.03 & 68.97 & 0.00 \\
\hline & UL1 & 30 & 82.9 & 484 & 5 & 255 & 224 & & 52.69 & 46.28 & 1.03 \\
\hline & UL2 & 31 & 63.0 & 8029 & 34 & 3024 & 4971 & & 37.66 & 61.91 & 0.42 \\
\hline & UL3 & 31 & 68.0 & 12281 & 121 & -1276 & 13436 & & -10.39 & 109.40 & 0.99 \\
\hline & UL4 & 30 & 88.8 & 6839 & 50 & -206 & 6995 & & -3.01 & 102.28 & 0.73 \\
\hline & UL5 & 31 & 180.0 & 11045 & 56 & 309 & 7680 & & 2.80 & 69.53 & 0.51 \\
\hline & UL6 & 30 & 239.0 & 3242 & 58 & -323 & 6507 & & -9.96 & 200.71 & 1.79 \\
\hline & UL7 & 46 & 297.4 & 9114 & 75 & -243 & 9282 & & -2.67 & 101.84 & 0.82 \\
\hline & UL8 & 31 & 254.0 & 1325 & 33 & -1421 & 2713 & 50479 & -107.25 & 204.75 & 2.49 \\
\hline & UL9 & 28 & 209.4 & 429 & 12 & -87 & 504 & 114978 & -20.28 & 117.48 & 2.80 \\
\hline
\end{tabular}


Table 7 (continued)

\begin{tabular}{|c|c|c|c|c|c|c|c|c|c|c|c|}
\hline \multirow[t]{2}{*}{ City } & \multirow[t]{2}{*}{ Phase } & \multirow{2}{*}{$\begin{array}{l}\text { No. of } \\
\text { days }\end{array}$} & \multirow{2}{*}{$\begin{array}{l}\text { Average } \\
\text { AQI }\end{array}$} & \multicolumn{5}{|c|}{ COVID-19 database } & \multicolumn{3}{|c|}{ COVID-19 impacts } \\
\hline & & & & $\begin{array}{l}\text { Positive } \\
\text { confirmed } \\
\text { cases }\end{array}$ & $\begin{array}{l}\text { Deceased } \\
\text { cases }\end{array}$ & $\begin{array}{l}\text { Active } \\
\text { cases }\end{array}$ & $\begin{array}{l}\text { Recovered } \\
\text { cases }\end{array}$ & $\begin{array}{l}\text { Vaccination } \\
\text { cases }\end{array}$ & $\begin{array}{l}\text { Activity } \\
\text { ratio }\end{array}$ & $\begin{array}{l}\text { Recovery } \\
\text { ratio }\end{array}$ & $\begin{array}{l}\text { Case } \\
\text { fatality } \\
\text { ratio }\end{array}$ \\
\hline & UL10 & 31 & 229.0 & 13874 & 40 & 10139 & 3695 & 308152 & 73.08 & 26.63 & 0.29 \\
\hline \multirow{14}{*}{ Thiruvananthapuram } & LD1 & 21 & 62.3 & 0 & 0 & 0 & 0 & & & & \\
\hline & LD2 & 19 & 54.9 & 17 & 1 & 2 & 14 & & 11.76 & 82.35 & 5.88 \\
\hline & LD3 & 14 & 59.9 & 0 & 0 & -2 & 2 & & & & \\
\hline & LD4 & 14 & 52.1 & 44 & 1 & 41 & 2 & & 93.18 & 4.55 & 2.27 \\
\hline & UL1 & 30 & 45.3 & 150 & 3 & 42 & 105 & & 28.00 & 70.00 & 2.00 \\
\hline & UL2 & 31 & 30.0 & 4281 & 7 & 2965 & 1305 & & 69.26 & 30.48 & 0.16 \\
\hline & UL3 & 31 & 42.0 & 11055 & 79 & 2177 & 8778 & & 19.69 & 79.40 & 0.71 \\
\hline & UL4 & 30 & 49.0 & 18933 & 135 & 5683 & 13105 & & 30.02 & 69.22 & 0.71 \\
\hline & UL5 & 31 & 70.5 & 24240 & 178 & -2275 & 26326 & & -9.39 & 108.61 & 0.73 \\
\hline & UL6 & 30 & 85.5 & 13297 & 141 & -4629 & 17509 & & -34.81 & 131.68 & 1.06 \\
\hline & UL7 & 46 & 58.5 & 14648 & 148 & -741 & 15486 & & -5.06 & 105.72 & 1.01 \\
\hline & UL8 & 31 & 78.0 & 12144 & 100 & 633 & 11402 & 45484 & 5.21 & 93.89 & 0.82 \\
\hline & UL9 & 28 & 60.3 & 6008 & 62 & -2338 & 8279 & 137285 & -38.91 & 137.80 & 1.03 \\
\hline & UL10 & 31 & 59.6 & 8953 & 49 & 3287 & 5104 & 494791 & 36.71 & 57.01 & 0.55 \\
\hline \multirow[t]{14}{*}{ Visakhapatnam } & LD1 & 21 & 67.2 & 0 & 0 & 0 & 0 & & & & \\
\hline & LD2 & 19 & 54.7 & 29 & 0 & 9 & 20 & & 31.03 & 68.97 & 0.00 \\
\hline & LD3 & 14 & 47.2 & 46 & 1 & 32 & 13 & & 69.57 & 28.26 & 2.17 \\
\hline & LD4 & 14 & 81.6 & 26 & 0 & -11 & 37 & & -42.31 & 142.31 & 0.00 \\
\hline & UL1 & 30 & 81.2 & 441 & 2 & 255 & 184 & & 57.82 & 41.72 & 0.45 \\
\hline & UL2 & 31 & 50.0 & 9240 & 102 & 7789 & 2332 & & 84.30 & 25.24 & 1.10 \\
\hline & UL3 & 31 & 49.0 & 26912 & 184 & -747 & 26492 & & -2.78 & 98.44 & 0.68 \\
\hline & UL4 & 30 & 64.0 & 13334 & 143 & -3571 & 16762 & & -26.78 & 125.71 & 1.07 \\
\hline & UL5 & 31 & 153.0 & 5785 & 77 & -1833 & 7541 & & -31.69 & 130.35 & 1.33 \\
\hline & UL6 & 30 & 167.0 & 2350 & 32 & -1135 & 3453 & & -48.30 & 146.94 & 1.36 \\
\hline & UL7 & 46 & 278.0 & 1334 & 16 & -617 & 1935 & & -46.25 & 145.05 & 1.20 \\
\hline & UL8 & 31 & 172.4 & 429 & 7 & -143 & 565 & 31066 & -33.33 & 131.70 & 1.63 \\
\hline & UL9 & 28 & 115.2 & 370 & 4 & 71 & 256 & 80829 & 19.19 & 69.19 & 1.08 \\
\hline & UL10 & 31 & 129.0 & 6129 & 24 & 3534 & 2809 & 316674 & 57.66 & 45.83 & 0.39 \\
\hline
\end{tabular}

Acknowledgements The authors thank their respective working organizations for the help and support rendered during this study.

Author contribution MV contributed in performing data analysis and writing the manuscript; NN contributed in the collection of literature, and writing and reviewing the manuscript; SMS, RK, ADR and ABB contributed in data collection and analysis. All the authors read and approved the final manuscript.

Data Availability Not applicable

\section{Declarations}

Ethics approval and consent to participate Not applicable

\section{Consent for publication Not applicable}

Competing interests The authors declare no competing interests.
Abbreviations $A N O V A$, Analysis of variance; $A O D$, Aerosol optical depth; $A Q I$, Air quality index; $A R M A$, Autoregressive moving average; $B L D$ 1, Pre-lockdown phase 1; $B L D$ 2, Pre-lockdown phase 2; $B L D$ 3, Pre-lockdown phase 3; $C O$, Carbon monoxide; $C P C B$, Central Pollution Control Board; $E F$, Exceedance factor; $K D E$, Kernel density estimation; $L D$ 1, Lockdown period phase $1 ; L D 2$, Lockdown period phase $2 ; L D 3$, Lockdown period phase 3; $L D$ 4, Lockdown period phase 4; NAAQS, National ambient air quality standards; $N A Q I$, National air quality index; $\mathrm{NCT}$, National capital territory; $\mathrm{Ni}$, Nickel; $\mathrm{NH}_{3}$, Ammonia; $\mathrm{NO}_{2}$, Nitrogen dioxide; $\mathrm{O}_{3}$, Ozone; $\mathrm{Pb}$, Lead; $P M_{2.5}$, Particulate matter 2.5 $\mu \mathrm{m} ; P M_{10}$, Particulate matter $10 \mu \mathrm{m} ; \mathrm{SO}_{2}$, Sulphur dioxide; $S O P$, Standard operating protocols; WHO, World Health Organization; WTC, Wavelet transform coherence

\section{References}

Agarwal A, Kaushik A, Kumar S, Mishra RV (2020) Comparative study on air quality status in Indian and Chinese cities before and during the COVID-19 lockdown period. Air Qual Atmos Health 13:11671178. https://doi.org/10.1007/s11869-020-00881-z 
Ambade B, Sankar TK, Kumar A, Gautam AS, Gautam S (2021) COVID-19 lockdowns reduce the Black carbon and polycyclic aromatic hydrocarbons of the Asian atmosphere: source apportionment and health hazard evaluation. Environ Dev Sustain 23: 12252-122271

Balakrishnan K, Cohen A, Smith KR (2014) Addressing the burden of disease attributable to air pollution in India: the need to integrate across household and ambient air pollution exposures. Environ Health Perspect 122:A6-A7. https://doi.org/10.1289/ehp.1307822

Bao R, Zhang A (2020) Does lockdown reduce air pollution? Evidence from 44 cities in northern China. Sci Total Environ 731:39052. https://doi.org/10.1016/j.scitotenv.2020.139052

Beig G, Rathod A, Tikle S, Maji S, Shobana SB (2021) Association of retreating monsoon and extreme air pollution in a megacity. $\mathrm{J}$ Environ Sci 106:97-104

Bera B, Bhattacharjee S, Shit PK, Sengupta N, Saha S (2021) Significant impacts of COVID-19 lockdown on urban air pollution in Kolkata (India) and amelioration of environmental health. Environ Dev Sustain 23:6913-6940

Bherwani H, Nair M, Musugu K, Gautam S, Gupta A, Kapley A, Kumar R (2020) Valuation of air pollution externalities: comparative assessment of economic damage and emission reduction under COVID-19 lockdown. Air Qual Atmos Health 13:683-694. https://doi.org/10.1007/s11869-020-00845-3

Bilal M, Khan MI, Nazir MS, Ahmed I, Iqbal HM (2020) Coronaviruses and COVID-19-complications and lessons learned for the future. J Pure Appl Microbiol 14(1):725-731

Chen H, Guo J, Wang C, Luo F, Yu X, Zhang W, Li J, Zhao D, Xu D, Gong Q, Liao J, Yang H, Hou W, Zhang Y (2020) Clinical characteristics and intrauterine vertical transmission potential of COVID19 infection in nine pregnant women: a retrospective review of medical records. Lancet 20:30360-30363

CPCB (2016) Annual Report 2015-16. http://cpcb.nic.in/annual-report. php

Das M, Das A, Sarkar R, Saha S, Mandal P (2021) Regional scenario of air pollution in lockdown due to COVID-19 pandemic: evidence from major urban agglomerations of India. Urban Clim 37:100821

Dutheil F, Baker JS, Navel V (2020) COVID-19 as a factor influencing air pollution? Environ Pollut 263:114466

Dutta S, Ghosh S, Dinda S (2021) Association between different factors: a comparative study among Delhi, Kolkata and Chennai megacity of India. Aerosol Sci Eng 5:93-111

Gautam S (2020) The influence of COVID - 19 on air quality in India: a boon or inutile. Bull Environ Contam Toxicol 104(6):724-726

Gautam AS, Dilwaliya NK, Srivastava A, Kumar S, Bauddh K, Siingh D, Shah MA, Singh K, Gautam S (2020) Temporary reduction in air pollution due to anthropogenic activity switch-off during COVID19 lockdown in northern parts of India. Environ Dev Sustain 23: 8774-8797. https://doi.org/10.1007/s10668-020-00994-6

Gautam AS, Kumar S, Gautam S, Anand A, Kumar R, Joshi A, Bauddh K, Singh K (2021) Pandemic induced lockdown as a boon to the Environment: trends in air pollution concentration across India. Asia-Pacific J Atmos Sci 1:1-16. https://doi.org/10.1007/s13143021-00232-7

Girdhar A, Kapur H, Kumar V, Kaur M, Singh D, Damasevicius R (2021) Effect of COVID-19 outbreak on urban health and environment. Air Quality Atmos Health 14:389-397

Gorbalenya AE, Baker SC, Baric R, Groot RJD, Drosten C, Gulyaeva $\mathrm{AA}$ et al (2020) Severe acute respiratory syndrome-related coronavirus: the species and its viruses-a statement of the Coronavirus Study Group. Nat Microbiol 5:536-544. https://doi.org/10.1101/ 2020.02.07.937862

Gouda KC, Singh P, Nikhilasuma P, Benke M, Kumari R, Agnihotri G, Kiran MH, Chandrika M, Rao KB, Ramesh V, Himesh S (2021) Assessment of air pollution status during COVID-19 lockdown
(March - May 2020) over Bangalore city in India. Environ Monit Assess 193:395

Kolluru SSR, Patra AK, Nazneen NSMS (2021) Association of air pollution and meteorological variables with COVID-19 incidence: evidence from five megacities in India. Environ Res 195:110854

Kumari P, Toshniwal D (2020) Impact of lockdown measures during COVID-19 on air quality-a case study of India. Int J Environ Health Res 16:1-8. https://doi.org/10.1080/09603123.2020. 1778646

Kutralam-Muniasamy G, Pérez-Guevara F, Roy PD, Elizalde-Martínez I, Shruti VC (2021) Impacts of the COVID-19 lockdown on air quality and its association with human mortality trends in megapolis Mexico City. Air Qual Atmos Health 14(4):553-562

Link 1 (2021) https://www.thehindu.com/data/covid-19-state-wisetracker-for-coronavirus-cases-deaths-and-testing-rates/ article31248444.ece?homepage=true. Accessed on 28.04.2021

Link 2 (n.d.) https://en.wikipedia.org/wiki/COVID-19_lockdown_in_ India. Accessed 10.5.2021

Link 3 (n.d.) https://www.ndtv.com/india-news/coronavirus-full-list-ofred-orange-green-districts-in-india-2221473. Accessed 10.5.2021

Link 4 (n.d.) https://www.statista.com/statistics/1114402/india-districtsin-covid-19-zones-by-state/. Accessed 10.5.2021

Link 5 (n.d.) https://swachhindia.ndtv.com/coronavirus-lockdown-3-0explained-what-are-red-orange-green-and-containment-zones44287/. Accessed 10.5.2021

Link 6 (2021) https://app.cpcbccr.com/ccr/\#/caaqm-dashboard/caaqmlanding. Accessed on 21.04.2021

Link 7 (2021) https://app.cpcbccr.com/AQI_India/. Accessed on 21.04. 2021

Link 8 (2021) https://www.covid19india.org/. Accessed on 25.04.2021

Louati A, Son LH, Chabchoub H (2018) Smart routing for municipal solid waste collection: a heuristic approach. J Ambient Intell Humaniz Comput 10:1865-1884. https://doi.org/10.1007/s12652018-0778-3

Mahato S, Pal S, Ghosh KG (2020) Effect of lockdown amid COVID-19 pandemic on air quality of the megacity Delhi, India. Sci Total Environ 730:139086

Mandal I, Pal S (2020) COVID-19 pandemic persuaded lockdown effects on environment over stone quarrying and crushing areas. Sci Total Environ 732:139281. https://doi.org/10.1016/j.scitotenv.2020. 139281

Markandeya VPK, Mishra V, Singh NK, Shukla SP, Mohan D (2021) Spatio-temporal assessment of ambient air quality, their health effects and improvement during COVID-19 lockdown in one of the most polluted cities of India. Environ Sci Pollut Res 28:10536 10551. https://doi.org/10.1007/s11356-020-11248-3

Menut L, Bessagnet B, Siour G, Mailler S, Pennel R, Cholakian A (2020) Impact of lockdown measures to combat Covid-19 on air quality over western Europe. Sci Total Environ 741:140426

Mishra M, Kulshrestha UC (2021) A brief review on changes in air pollution scenario over South Asia during COVID-19 lockdown. Aerosol Air Qual Res 21:200541. https://doi.org/10.4209/aaqr. 200541

Mor S, Kumar S, Singh T, Dogra S, Pandey V, Ravindra K (2021) Impact of COVID-19 lockdown on air quality in Chandigarh, India: understanding the emission sources during controlled anthropogenic activities. Chemosphere 263:127978

Panda S, Mallik C, Nath J, Das T, Ramasamy B (2021) A study on variation of atmospheric pollutants over Bhubaneswar during imposition of nationwide lockdown in India for the COVID-19 pandemic. Air Qual Atmos Health 14(1):97-108

Pant G, Alka GD, Gaur A, Hossain K, Singh SV, Gupta AK (2020) Air quality assessment among populous sites of major metropolitan cities in India during COVID-19 pandemic confinement. Environ Sci Pollut Res 27:44629-44636. https://doi.org/10.1007/s11356-02011061-y 
Ramasamy K, Jayakumar S (2020) The trend of COVID-19 at Bengaluru: prediction to continue the better epidemic management. Int J Curr Res Rev 12(13):56-60

Ranjan AK, Patra AK, Gorai AK (2020) Effect of lockdown due to SARS COVID-19 on aerosol optical depth (AOD) over urban and mining regions in India. Sc Total Environ 745:141024

Ravindra K, Singh T, Biswal A, Singh V, Mor S (2021) Impact of COVID-19 lockdown on ambient air quality in megacities of India and implication for air pollution control strategies. Environ Sci Pollut Res 28:21621-21632. https://doi.org/10.1007/s11356-02011808-7

Ropkins K, Tate JE (2021) Early observations on the impact of the COVID-19 lockdown on air quality trends across the UK. Sci Total Environ 754:142374

Roy S, Singha N (2020) Analysis of ambient air quality based on exceedance factor and air quality index for Siliguri City, West Bengal. Curr World Environ 15(2):235

Saadat S, Rawtani D, Hussain CM (2020) Environmental perspective of COVID-19. Sci Total Envir 728:138870

Sathe Y, Gupta P, Bawase M, Lamsal L, Patadia F, Thipse S (2021) Surface and satellite observations of air pollution in India during COVID-19 lockdown: implication to air quality. Sustain Cities Soc 66:102688

Selvi SM, Kesavan R, Arun DR, Anushya BB, Natarajan N, Vasudevan M (2020) Assessment of air quality index in major cities of India lessons from Lockdown. IOP Conf. Ser. Mat Sci Eng 955:012079

Sharma M, Jain S, Lamba BY (2019) Epigrammatic study on the effect of lockdown amid COVID-19 pandemic on air quality of most polluted cities of Rajasthan (India). Air Qual Atmos Health 13:1157-1165. https://doi.org/10.1007/s11869-020-00879-7

Sharma R, Kumar R, Sharma DK, Son LH, Priyadarshini I, Pham BT, Bui DT, Rai S (2020) Inferring air pollution from air quality index by different geographical areas: case study of India. Air Qual Atmos Health 12:1347-1357. https://doi.org/10.1007/s11869-019-00749-x

Sharma GD, Bansal S, Yadav A, Jain M, Garg I (2021) Meteorological factors, COVID-19 cases, and deaths in top 10 most affected countries: an econometric investigation. Environ Sci Pollut Res 28: 28624-28639. https://doi.org/10.1007/s11356-021-12668-5
Shehzad K, Sarfraz M, Shah SGM (2020) The impact of COVID-19 as a necessary evil on air pollution in India during the lockdown. Environ Pollut 266:115080

Singh V, Singh S, Biswal A, Kesarkar AP, Mor S, Ravindra K (2020a) Diurnal and temporal changed in air pollution during COVID-19 strict lockdown over different regions of India. Environ Pollut 266:115368

Singh V, Singh S, Biswal A, Kesarkar AP, Mor S, Ravindra K (2020b) Diurnal and temporal changes in air pollution during COVID-19 strict lockdown over different regions of India. Environ Pollut 266:115368

Tyagi B, Choudhury G, Vissa NK, Singh J, Tesche M (2021) Changing air pollution scenario during COVID-19: redefining the hotspot regions over India. Environ Pollut 271:116354

Vadrevu KP, Eaturu A, Biswas S, Lasko K, Sahu S, Garg JK, Justice C (2020) Spatial and temporal variations of air pollution over 41 cities of India during the COVID-19 lockdown period. Sci Rep 10(1):115

Vali M, Hassanzadeh J, Mirahmadizadeh A, Hoseini M, Dehghani S, Maleki Z, Méndez-Arriaga F, Ghaem H (2021) Effect of meteorological factors and air quality index on the COVID-19 epidemiological characteristics: an ecological study among 210 countries. Environ Sci Pollu Res 22:1-11. https://doi.org/10.1007/s11356021-14322-6

Wang C, Horby PW, Hayden FG, Gao GF (2020) A novel coronavirus outbreak of global health concern. The Lancet 395(10223):470-473

Wiśniewski O, Kozak W, Wiśniewski M (2021) The ground-level ozone concentration is inversely correlated with the number of COVID-19 cases in Warsaw, Poland. Air Qual Atmos Health 14:1169-1173. https://doi.org/10.1007/s11869-021-01009-7

Yuda M (2019) Asian countries rush to fight toxic air pollution. Accessed from

Zambrano-Monserrate MA, Ruano MA, Sanchez-Alcalde L (2020) Indirect effects of COVID-19 on the environment. Sci Total Environ 728:138813

Publisher's note Springer Nature remains neutral with regard to jurisdictional claims in published maps and institutional affiliations. 